\title{
Constancia y fluctuaciones: una mirada al discurso de la política exterior costarricense ante la Asamblea General de las Naciones Unidas (2002-2015)
}

\section{Carlos Humberto Cascante Segura*}

\section{RESUMEN}

El artículo analiza el discurso de política exterior de Costa Rica en el Debate General de la Asamblea General de Naciones Unidas (AGONU). Para ello se recurre a una propuesta teórica basada en el comportamiento de los pe-queños estados, el manejo y desarrollo del poder blando, así como el discurso como instrumento de ese tipo de poder. Metodológicamente, se emplea un método de análisis de contenido mixto, donde el componente cuantitativo se desarrolla a partir del software científico "Wordsmith 6.0", cuyos resultados numéricos se estudian a partir del análisis cualitativo de conceptos. A partir de ambas propuestas se establece la existencia de cuatro categorías fun-damentales del discurso costarricense en ese foro: "derechos humanos", "derecho internacional", "desarme", así como "protección del medio ambiente y desarrollo." A partir de la determinación de estas se analizan los cambios y continuidades a lo largo de más de una década, lo que permite determinar que existe constancia en las categorías, pero fluctuaciones en la intensidad de su uso y en el contenido. La fluctuación, por consiguiente, es paradójicamen-te una constante en discurso costarricense, por lo que incluso iniciativas multilaterales vinculadas a las categorías descritas como el Consenso de Costa Rica (desarme-desarrollo) y Paz con la Naturaleza (ambiente) fueron despla-zadas, pese a que su contenido continuó de alguna forma en el discurso, lo que muestra una de las debilidades del discurso de política exterior costarricense: su falta de constancia para construir entramados conceptuales más sóli-dos. Por otra parte, la intensidad con que se usa cada una de estas categorías se encuentra claramente vinculado con los intereses propios que tenga cada gobierno, sin que importe mucho el partido político a que este pertenezca. Se concluye, por ende, que la falta de constancia relativa en el contenido de las categorías tiende a debilitar el poder blando costarricense en tales espacios.

\section{Palabras clave}

Discurso; estado pequeño; política exterior; Costa Rica; influencia internacional.

\section{TitLe}

Constancy and fluctuations: a perspective of Costa Rican foreign policy discourse at the United Nations General Assembly (2002-20I5)

\section{Extended Abstract}

The article analyzes the Costa Rica foreign policy discourse in the speeches issued in the General Debate of the United Nations General Assembly (UNGA). In order to complete this objective, this text is based on a theoretical proposal compounded by the behavior of small states, the management and development of soft power, as well as the 'speech' as an instrument of how that type of power is used. From this perspective,"small states" have different strategies to achieve their objectives in the international system. One of them is to increase its "soft power", but to achieve some success in this goal depends on the ability of the "small state" to maximize its presence in interna-tional society, for which they must establish a certain degree of influence in various international forums and clearly define its foreign policy objectives to consolidate its "soft power".

One of the most important tools to increase "soft power" capacities is the use of "discourse". In this sense, "dis-course" is not only an expression of values and prejudices, but also one of the methods to create them. For this reason, to study the different levels of political discourse has been a very important approach for studies in con-temporary international relations.Also, discourses in general, and foreign policy discourse in particular, change throughout time, and these changes can

DOI:

https://doi.org// 0.15366/relacionesinternacionales2021.48.008

Formato de citación recomendado:

CASCANTE SEGURA, Carlos Humberto (202I). "Constancia y fluctuaciones: una mirada al discurso de la política exterior cos-tarricense ante la Asamblea General de las Naciones Unidas (2002-2015)”, Relaciones Internacionales, $\mathrm{n}^{\circ} 48$, pp. $143-172$.
* Carlos Humberto CASCANTE SEGURA,

Costarricense, candidato doctoral en Historia por la Universidad de Costa Rica, posee una maestría en Historia y otra en Diplomacia por la Universidad de Costa Rica. Profesor de la Escuela de Relaciones Internacionales de la Universidad Nacional y la Escuela de Ciencias Políticas de la Universidad de Costa Rica. Sus líneas de investigación son la historia global e historia de las relaciones internacionales de Costa Rica y Centroamérica. Contacto: car-los. cascante.segura@ una.ac.cr

\section{Recibido:}

30.11.2020

Aceptado:

22.07.202। 
be linked with research on foreign policy change and continuity, exposing internal and external factors as transformational causes in foreign policy. In the Latin American case, recent litera-ture has indicated that the main changes are caused by "presidential preferences" more than any other factors.

This general approach is the main reason for the methodological approach chosen to do this research. It is based on a mixed content analysis method, where the quantitative component is developed from the scientific software "Wordsmith 6.0", whose numerical results are studied from the qualitative analysis of concepts. The documental corpus for this research is composed of the speeches given by Costa Rican representatives to the General Debate of the United Nations General Assembly (most of the time President of the Republic or Ministers of Foreign Affairs, in a few cases vice-presidents or viceministers of Foreign Relations have been selected). Thus, the corpus is made up of speeches issued from 2002 to 2015 , these correspond to the administrations of Abel Pacheco de la Espriella (2002-06) of the Social Christian Unity Party (PUSC) (four texts), Oscar Arias Sanchez (2006-I0) and Laura Chin-chilla Miranda (2010-14), both from the National Liberation Party (PLN) (eight texts), and the first two years of the administration Luis Guillermo Solís Rivera (2014-18) of the Citizen Action Party (PAC) (two texts).

Based on the collected evidence, it is possible to establish four fundamental categories of Costa Rican discourse in UNGA: "human rights protection","international law","disarmament", as well as "protection of the environment and development." The effects of the development of a national identity that is established in foreign relations could be an interesting link to explain the appearance of these categories and their preservation. This component can be fundamental to understand to what degree Costa Rican positions are strengthened and legitimized in the interna-tional sphere as a small state, as well as the good credentials that it has regularly had on issues generally accepted by most of the international community.

Moreover, following to this exposition, it has been possible to establish the changes and continuities in the content and intensity of these concepts in over more than a decade of speeches.According to this analysis it is possible to argue that in spite of the constancy in the categories, there are also strong fluctuations in the intensity of their use and in the content that Costa Rican authorities have included within then.

Along these lines, human rights were widely used during the first four years of the period covered by this research (Pacheco Administration, 2002-2005), but its presence is clearly reduced during the rest of the time. Disarmament was the fundamental category for the next four years (Arias administration, 2006-2009), but it is less important during the rest of the period. Meanwhile, "international law" follows a constant line, even though a lower frequency of use is evident compared to other categories. Finally, "protection of the environment and development" has ups and downs throughout the corpus, but it tends to increase in those years with large international conferences or meetings on this matter.

The change of administrations seems to be a central element to explain these changes. Thus, for example, the Pacheco Administration (2002-2006) focused on human rights (from a conservative approach), the Arias Admin-istration (200620I0) on disarmament, the Chinchilla Administration (2010-20I4) on international law (this is clear linked with the border and political conflict with Nicaraguan Government, this incident was presented by Costa Rica in UNGA, OAS and the International Court of Justice) along with the environment and development; while the Solís Administration (20I4-20I8) returned to human rights along with the environment and development. Moreover, par-ty identity does not ensure the continuity of the content and intensity of the categories. The only time in which there was a consecutive repetition of a political party in the Executive during the period under study (2006-20I0 and 20I0-20I4), the Chinchilla Administration gave less importance to disarmament than the Arias administration, also internal party conflicts and separations of important personalities can provoke ruptures in the discourse content.

Fluctuation, therefore, is paradoxically a constant in Costa Rican discourse. Even multilateral initiatives linked to the categories described as the Costa Rica Consensus ("Consenso de Costa Rica") (development) and Peace with Na-ture ("Paz con la Naturaleza") (environment) were displaced, even though their content continued in some way through the discourse, which shows one of the weaknesses of the Costa Rican foreign policy discourse: its lack of constancy.This could come from changes in the leadership of Costa Rican diplomacy, ideological variants when there is a change in the political party in power, or characteristics of the leadership of President of the Republic or in the Ministry of Foreign Affairs. The international agenda also constitutes a determining factor for the content of the discourse. In the Costa Rican case, as a small country, such a situation is more evident given that the large international events, especially those aimed at addressing issues that reinforce the categories of discourse, would be essential to understand the fluctuations of discourse.

\section{KEYWORDS}

Discourse; small state; foreign policy; Costa Rica; international influence. 


\section{ntroducción}

Como otros estados calificados como pequeños (small states), Costa Rica se ha caracterizado en diversos foros por participar en diversas iniciativas y el posicionamiento de ciertos valores. Uno de los elementos centrales para establecer sus posiciones, al igual que otros "estados pequeños", ha sido el discurso político en foros de alta relevancia como la Asamblea General de Naciones Unidas, el Consejo de Seguridad (del cual ha sido miembro en tres ocasiones) o el Consejo de Derechos Humanos. De tal forma, en el marco de los estudios que pretenden acercarse al análisis de las conductas y las herramientas mediante las cuales los estados pequeños alcanzan sus propósitos, este artículo tiene como objetivo estudiar las características del discurso de la política exterior costarricense en el Debate General de la Asamblea de las Naciones Unidas en el periodo comprendido entre 2002 y 2015.

La investigación que se plantea a continuación tiene como premisa que es factible analizar cómo un estado pequeño, como Costa Rica, posiciona su imagen y valores dentro de un foro multilateral importante, mediante el análisis de contenido de sus discursos. Al igual que cualquier acercamiento al comportamiento de actores políticos, este tipo de abordaje tiene limitaciones, dado que se concentra en un periodo relativamente corto de tiempo y abarca un único foro internacional, que no necesariamente está compaginado con la agenda bilateral o regional en que Costa Rica también tiene intereses. No obstante, permite observar un ámbito especialmente relevante para un país que se define como un socio constante y responsable en el multilateralismo (MREC, 2005). Asimismo, no se pretende establecer explicaciones definitivas a los cambios y continuidades del discurso costarricense en este foro, dado que ese implicaría un estudio específico con ese fin y el abordaje de otras fuentes, lo que no obsta a que las constantes y fluctuaciones queden debidamente evidenciados; así como que se presenten algunas hipótesis sobre factores que pudieron provocarlas.

Desde esta perspectiva, el discurso político constituye una de las herramientas relevantes que tienen los actores internacionales para cumplir sus objetivos en diversos ámbitos de interrelación de la comunidad internacional. Este interés se fundamenta en la relevancia que ha recuperado desde hace varias décadas el discurso en el estudio del comportamiento de los actores (individuales y colectivos), lo que ha permitido un desarrollo cada vez más basto de este tipo de enfoques, así como el desarrollo de diversas metodologías y herramientas informáticas.

Para tal fin, el artículo se estructura en siete apartados: el primero y segundo se dedican a la propuesta teórica y la propuesta metodológica, respectivamente; los siguientes cinco se dedican a las principales categorías detectadas en el discurso costarricense, en cada uno se estudia la evolución de su contenido. Por último, se establecen algunas conclusiones sobre los efectos que las características del discurso costarricense producen en su política exterior.

\section{Propuesta teórica: estados pequeños, poder blando y discurso político}

Este apartado teórico definirá y establecerá las interacciones entre los conceptos de comportamiento de los small states, "poder blando" y el discurso como instrumento de la política exterior; para luego establecer los instrumentos metodológicos que se emplearán para su estudio 
y una descripción pormenorizada del corpus empleado.

En las últimas décadas, la literatura sobre estados pequeños ha sido abundante, dado el interés por comprender cómo sobreviven en una sociedad internacional en que el realismo sigue siendo predominante en los cálculos del comportamiento (Maass, 20I4). Desde esta perspectiva, la definición de lo que es un estado pequeño no resulta pacífica, pues pueden utilizarse criterios demográficos, geográficos, aquellos vinculados con sus capacidades para garantizar por sí mismos su supervivencia (Galal, 2020, pp. 4I-42) y, por último, la tesis constructivista, según la cual la definición de un estado como pequeño depende la relación y la percepción que existe en un estado y el resto de los actores que integran la sociedad internacional (Murillo, 2008, p. 88).

Aceptando que el poder constituye una relación dinámica y relativa, el análisis constructivista permite establecer diversas variables que condicionan el comportamiento externo y señalan la existencia de diversos posicionamientos para conseguir los objetivos planteados. Desde esta perspectiva, siguiendo a Abo Lila (citado por Galal, 2017, p. 53), los estados pequeños tienen cuatro posibles estrategias no excluyentes entre sí para conseguir sus objetivos, estas son:

(a) El ligamen absoluto a una potencia de superiores capacidades, para ello el estado pequeño debe demostrar al otro actor la defensa de los intereses del pequeño forma parte de la protección de los intereses del estado más poderoso.

(b) El desarrollo de un nicho de acción que destaque a ese estado por sobre otros actores internacionales, lo que le permite brindar a la comunidad internacional un beneficio que a su vez puede intercambiar por otros intereses.

(c) El desarrollo de medios para generar "poder blando", lo que permite establecer ciertos beneficios al granjearse la buena voluntad de los otros actores internacionales o de la opinión pública en diversos ámbitos.

(d) Consolidación interna, que permite resistir las presiones externas de actores más poderosos.

Conseguir algún éxito con la segunda y tercera estrategia depende, por consiguiente, de la capacidad que tenga el "estado pequeño" para maximizar su presencia en la sociedad internacional, para lo que deben establecer cierto de grado de influencia en diversos foros internacionales y definir con claridad sus objetivos de política exterior para consolidar su "poder blando" (Chong, 2010; Thorhallsson, 2012; Ó Súilleabháin, 20I4). Esta meta implica establecer cierta regularidad de los componentes de la política exterior, tanto desde el punto de vista discursivo como desde las acciones concretas que se tomen en estos ámbitos (votaciones, participación en comisiones, propuestas de trabajo, entre otros) que amplifiquen su capital moral, basado en la reputación con que maneja los asuntos domésticos y su comportamiento internacional (Chong, 2010, p. 387).

El argumento expuesto por Chong lleva necesariamente a una corta reflexión del significado de este concepto de amplia difusión en la literatura sobre asuntos internacionales. Nye, a quien se tiene como acuñador del término, define al "poder blando" como: 
"la habilidad de obtener lo que quieres a través de la atracción antes que a través de la coerción o de las recompensas. Surge del atractivo de la cultura de un país, de sus ideales políticos y de sus políticas" (Nye, 2010, p. II8)!.

Bajo esa perspectiva, el "poder blando" implica la capacidad de influir sobre el comportamiento de otros actores mediante mecanismos distintos al uso de la fuerza, la capacidad económica y otros mecanismos tradicionales de las interacciones entre actores internacionales. Entre estos recursos se encuentran la capacidad de para expresar ciertos valores como parte de la cultura política de un país y que condicionan sus relaciones con otros, de forma tal que las ideas seleccionadas por el emisor influyan tanto en interlocutores cercanos, como en la opinión pública de otros países.

Dado que el concepto el concepto de "poder blando" ha recibido constantes críticas, puesto que resulta vago al utilizarse como herramienta de análisis, se han hecho diversos esfuerzos por su instrumentalización. Algunos de estos han intentado establecerlo a partir de mecanismos empleados por los actores para generar "atracción", por ejemplo, los estudios sobre diplomacia pública, diplomacia cultural y la conformación de la "marca país” (Chitty, 2017, p. 20). Sin embargo, todos estos parten de la elaboración de un mensaje, que puede difundirse por distintos medios, es decir de un discurso, que puede definirse, siguiendo a van Dick, como:

“...un evento comunicativo específico. Ese evento es en sí mismo muy complejo, y al menos involucra a una cantidad de actores sociales, esencialmente en los roles de hablante/ escribiente y oyente/lector (pero también en otros roles, como observador o escucha), que intervienen en un acto comunicativo, en una situación específica (tiempo, lugar y circunstancias) y determinado por otras características del contexto. Este acto comunicativo puede ser escrito u oral y usualmente combina, sobre todo en la interacción oral, dimensiones verbales y no verbales (ademanes, expresiones faciales, etc.)" (Van Dick, 2006, p. 247).

Bajo esta perspectiva, algunos trabajos han enfatizado cómo todo proceso de consolidación de "poder blando" parte de la construcción de un discurso que asocia características positivas con el emisor y negativas a sus adversarios. Además, indagan sobre los distintos mecanismos de difusión y posicionamiento de este discurso en diferentes foros, que van desde la tradicional alocución hasta el uso de estrategias más complejas de comunicación (Hagström y Nordin, 2020; Benhaïm, y Öktem, 20I5).

Estos estudios tienen como base la relevancia que la investigación sobre el discurso tomó en las ciencias sociales en la segunda mitad del siglo pasado, cuando autores como Michel Foucault plantean su verdadero valor en la dinámica del poder, en esta línea, el filósofo francés plantearía que "el discurso no es simplemente aquello que traduce las luchas o los sistemas

La obra original de J. Nye data de 2004: Soft Power.The Means to Success in the World Politics (en Referencias). 
de dominación, sino aquello por lo que, y por medio de lo cual se lucha, aquel poder del que quiere uno adueñarse" (Foucault, 1992, p. 5). Aunque esta afirmación puede ser discutida y puede argumentarse que la fuerza perlocutiva del discurso se encuentra vinculada primordialmente con el ambiente institucional en que se desarrolla y el poder relativo de emisores y receptores, lo cierto es que el concepto amplio de discurso que se ha tomado de Van Dick permite un balance apropiado entre los elementos propios del lenguaje y del contexto en que este se formula.

A partir esta comprensión, se ha construido una valiosa relación entre lingüística y estudios políticos, que ha permitido dimensionar los diversos componentes del discurso con efectos de orden político. En esta línea, todo discurso político contiene "actos del habla" (speech acts) que pueden ser estudiados y que abarcan elementos (I) expresivos (establecen la complacencia, preocupación o disgusto con una situación), (2) representativos (aquellos que establecen hechos de la realidad para el emisor), (3) directivos (aquellos que solicitan o exigen la realización de ciertos comportamientos del receptor del mensaje), (4) comisivos (los que amenazan o prometen comportamientos futuros del emisor), y (5) declarativos (expresan el resultado de un acto que afecta al emisor o al receptor); (Chilton y Schäffner, 20II, pp. 305-307). En otras palabras, el discurso tiene implícita una función performativa, es decir, que produce acciones y genera efectos en la realidad (actos ilocutorios, la intención de lo que se dice; y perlocutorios, las reacciones que el mensaje causa en el receptor), por lo que constituye parte esencial del fenómeno político.

El estudio del discurso no ha quedado al margen de la disciplina de las Relaciones Internacionales (Baillat, Emprin, Ramel, 2018, p. 153). Por ejemplo, para finales de la década de 1980, Welsh Larson planteaba su utilización para determinar el sistema de creencia de los líderes políticos estadounidense durante los primeros estadios de la Guerra Fría, al tiempo que señalaba las limitaciones de un método puramente cuantitativo para comprender las dimensiones del discurso político y recomendaba un uso sistema mixto para abordar este tipo de temáticas (Welch Larson, 1988, pp. 249-250).

Recientemente, Broad, Daddow y Schnapper, para el caso británico, han señalado el carácter de los discursos como un medio indispensable para movilizar apoyo a una causa y generar consensos hacia posturas particulares (2010 y 2013). Asimismo, para el caso latinoamericano se encuentran algunos trabajos especialmente sobre la política exterior de los países sudamericanos, entre ellos los textos de Simonoff (1997) sobre los discursos e ideas del radicalismo argentino; así como el artículo de López y Silva sobre el discurso de política exterior de los partidos políticos en Uruguay y Brasil (2015). Igualmente relevante es el texto de Lustig (2016), quien intenta determinar el uso de "poder duro" o "poder suave", a partir de los discursos de política exterior de Brasil entre 1995 y 2010.

Por último, dado que los discursos costarricenses brindan un acercamiento a los continuidades y cambios en su comportamiento en la Asamblea General, resulta relevante reseñar algunos componentes teóricos sobre el cambio en la política exterior. Este constituye una parte importante de los estudios de análisis de política exterior,aunque se ha elaborado fundamentalmente a partir del estudio de las votaciones o el comportamiento específico ante situaciones diversas en el ámbito internacional (Alden y Aran, 2017, p. 14). En esta línea, Blavoukos y Bourantonis establecen una serie de posibles factores internos y externos para explicar el fenómeno. Dentro 
de los componentes internos se encuentran elementos institucionales y personales que rodean la toma de decisiones de política exterior, así como la existencia de grupos de presión con capacidad de incidencia en dicho proceso. Por otra parte, en los externos, se incluyen la influencia que sobre un actor tiene la participación en el sistema, como son el establecimiento de agendas generales o las presiones de otro actor (2014, pp. 487-490).

Para el caso latinoamericano, un reciente trabajo empírico de Merke, Reynoso y Schenoni (2020), pretende comprobar el peso de tres factores fundamentales para el cambio de política exterior en América Latina: la figura presidencial, las líneas partidarias y régimen político-electoral, por último, factores externos como eventos transformadores del sistema internacional (el final de la Guerra Fría y el I I-S), debilidad económica e influencia de los Estados Unidos. El estudio, realizado a partir de un proceso estadístico inferencial y teniendo como base una amplia encuesta de expertos, concluye que de las variables estudiadas la que tiene mayor peso estadístico son las “preferencias presidenciales”. Es decir, la política exterior en América Latina tiende a cambiar como consecuencia de la personalidad e ideología del gobernante y menos por las características ideológicas de los partidos o la influencia internacional. Aunque el estudio, por el tipo de fuente usada, tienen limitaciones si constituye un interesante aporte para debatir los resultados del trabajo empírico que se presenta en este texto.

\section{Propuesta metodológica: el análisis de contenido aplicado al caso de Costa Rica}

De acuerdo con el enfoque constructivista, Costa Rica puede ser considerado como un estado pequeño (Murillo, 2008) y, por consiguiente, en este trabajo se analizarán los componentes del discurso ante la Asamblea General de las Naciones Unidas, entre el año 2002 y el 20I5, es decir, en los años inmediatamente posteriores a los ataques terroristas en Nueva York y Virginia, que demostraron una arquitectura internacional distinta a la que se percibió en la década posterior al final de la Guerra Fría. Se pretende con este ejercicio establecer patrones de continuidad y cambio entre los textos en cuestión, como un indicador para determinar la fortaleza del discurso de política exterior costarricense a lo largo de dicho periodo, pese a los cambios regulares de gobiernos y la transición en estas funciones de diversas agrupaciones políticas.Así podría perfilarse si se cumplen en alguna medida los parámetros de regularidad necesarios para desarrollar alguna forma de poder blando, pese a la debilidad económica, militar y política que caracteriza a Costa Rica como estado pequeño.

Este tipo de abordaje es poco común en los estudios sobre política exterior en Costa Rica y la región centroamericana, de forma que existen pocos antecedentes que orienten este tipo de acercamiento a la política exterior de este país centroamericano. Por tal motivo, el abordaje de los textos y mensajes se ha desarrollado mediante el método de análisis de contenido, el cual constituye una de las herramientas más empleadas en las disciplinas sociales desde mediados del siglo anterior. Durante varias décadas, que algunos autores ubican entre 1940-1990 la consolidación de este provino del uso abordajes cuantitativos (análisis de frecuencia de palabras, relación de palabras, análisis de intensidad y valencias), que definieron al método como un ejercicio cuantitativo y que aún en la actualidad son utilizadas regularmente (Bardin, 2002; Neuendorf, 2002). Sin embargo, desde la década de los noventa del siglo anterior se ha criticado este enfoque, dado que el análisis 
puramente estadístico no toma en cuenta la dependencia del contexto (relaciones transtextuales y extratextuales) de los corpus documentales, los cambios en los significados de los conceptos a lo largo del tiempo, la especificidad de los lenguajes, los pesos relativos de los términos por sobre las frecuencias de estos, así como el valor de los silencios en los textos (Schreier, 20 I2; Mayring, 20 I4).

Para esta investigación se han seleccionado los discursos producidos por los representantes costarricenses ante la Asamblea General de las Naciones Unidas (la mayor parte del tiempo presidente de la República o ministros de Relaciones Exteriores, en algunos pocos casos vicepresidentes o viceministros de Relaciones Exteriores). De tal manera, el corpus se encuentra compuesto por los discursos emitidos desde 2002 hasta 2015, estos corresponden a las administraciones de Abel Pacheco de la Espriella (2002-06) del Partido Unidad Social Cristiana (PUSC) (cuatro textos), Óscar Arias Sánchez (2006-10) y Laura Chinchilla Miranda (20l0-14), ambos del Partido Liberación Nacional (PLN) (ocho textos) y los dos primeros años de la administración Luis Guillermo Solís Rivera (2014-18) del Partido Acción Ciudadana (PAC) (dos textos). Así, se abordan los planteamientos de tres diferentes partidos, el PLN, partido hegemónico de la política costarricense en la segunda mitad del siglo $X X, y$ el PUSC, que reunió a la oposición al PLN a partir de 1980, con lo que se conformó un sistema bipartidista, que se debilitó en la primera década del siglo XXI y permitió el surgimiento del PAC, que finalmente alcanza la presidencia en 2014.

El escenario en que se emiten estos discursos, el debate general de la Asamblea General de las Naciones Unidas, constituye un foro privilegiado, dado que en este se plantean las posturas fundamentales que un país establece en torno a su política exterior. Por consiguiente, con el paso de las décadas se ha transformado en una de las herramientas claves para establecer la imagen que cada país desea proyectar en el sistema internacional. Sobre la importancia de este foro en la utilización de la metodología de análisis de contenido sea señalado que:

"There are several important characteristics of GD speeches that have implications for their use in deriving estimates of state preferences from them. In contrast to UNGA rollcall votes, which are directly linked to the adoption of UN resolutions, GD speeches are not institutionally connected to decision-making within the UN. As a consequence, states face lower external constraints and pressures when delivering GD statements than when voting in the UNGA. Indeed, studies that use UNGA voting highlight the various constraints countries face when voting as a result of, among other things, aid relationships and strategic voting blocs (see Alesina and Dollar, 2000; Kim and Russett, 1996; Voeten, 2000). The lack of external constraints means that when delivering their GD statements, governments have more leverage with the positions they take and the issues they emphasise. Hence, GD statements provide more information on key national priorities tan the limited number of votes in the UNGA" (Baturo, Dassandi, Mikhaylov, p. 2). 
Para este este estudio se utilizó un método mixto, que permite brindar una mayor fiabilidad al proceso de investigación, similar al planteado por Alice Baillat, Fabien Emprin, and Frédéric Ramel (2018, p. I53). De tal forma, mediante el software WordSmith 6.0, se rescataron las combinaciones de dos palabras que con cercanía de 0 a 3 vocablos que se repiten con frecuencia superior a tres veces en el corpus (con la opción joint el programa en cuestión permite mostrar cuando dos vocablos se usas conjuntamente en cada uno de los textos) y se emplearán en al menos en tres de los 14 discursos por el que está compuesto el corpus. Una vez con dicho insumo se procedió a realizar una categorización conceptual emergente, esta proviene del estudio de las relaciones numéricas que produce el Wordsmith, que se presenta mediante tablas a lo largo del texto, así como del estudio cualitativo de los textos empleados, junto con los contextos internos y externos que el gobierno de turno enfrentó durante este periodo.

\section{Una revisión general de las categorías del discurso de política exterior costarricense en la Asamblea General de Naciones Unidas}

Del estudio realizado se desprende que predominan en el lenguaje empleado en los discursos costarricenses referencias constantes a cuatro categorías fundamentales en la elaboración de la imagen internacional del país en los últimos años: (I) derechos humanos, (2) derecho internacional, (3) desarme y (4) protección del ambiente ligada al desarrollo económico y social. Sin embargo, el propósito de estos procesamientos consiste en demostrar que la intensidad en el uso de estas categorías fluctúa de diversas a maneras a lo largo del periodo de estudio, pese a que se mantenga esa estructura general. Cabe menciona que estos componentes, salvo la protección del ambiente, han formado parte de los discursos oficiales del país desde la década de 1970 (Facio, 1977; MREC, 2005), lo que no implica que el contenido de estas categorías haya variado con el tiempo.

Cabe acotar que, aunque en los discursos estudiados también aparece una reiteración constante del vocablo paz (107 ocasiones) y seguridad (63); el uso de estos como la quinta categoría del discurso de política exterior costarricense, paz-seguridad, debe abordarse en un estudio separado; dado que su utilización se encuentra vinculada con la referencia a casos concretos que implican un proceso de análisis distinto al planteado para las otras cuatro categorías previamente indicadas. 
Tabla I.Total de repeticiones de combinaciones de pares de palabras en discursos de Costa Rica en la Asamblea General de las Naciones Unidas y total de discursos en que aparecen ordenados por categoría (2002-20 I 5)

\begin{tabular}{|c|c|c|c|c|}
\hline CATEGORIA ASIGNADA & PALABRA 1/PALABRA 2 & $\begin{array}{l}\text { Tatal de } \\
\text { repeticiones en el } \\
\text { corpus }\end{array}$ & $\begin{array}{l}\text { Total de discursos } \\
\text { en que aparecen }\end{array}$ & $\begin{array}{l}\text { \% de disturses en } \\
\text { que aparecen }\end{array}$ \\
\hline DERECHOS HUMANOS & HUMANOS/DERECHOS & 57 & 13 & 86.7 \\
\hline AMBIENTE-DESARROLLO & DESARROLLO/SOSTENIBLE & 30 & 12 & 80.0 \\
\hline DERECHO INTERNACIONAL & INTERNACIONAL/DERECHO & 26 & 11 & 73.3 \\
\hline DESARME & GASTO/MILITAR & 20 & 7 & 46.7 \\
\hline DERECHO INTERNACIONAL & INTERNACIONAL/CORTE & 20 & 10 & 66.7 \\
\hline DESARME & APMAS/NUCLEARES & 17 & 6 & 40.0 \\
\hline AMBIENTE-DESARROLLO & CAMBIO/CUMÁTICO & 16 & 7 & 46.7 \\
\hline AMBIENTE-DESARROLLO & DESARROLLO/MILENIO & 13 & 8 & 53.3 \\
\hline DESARME & ARMAS/TRANSFERENCLA & 13 & 9 & 60.0 \\
\hline DERECHOS HUMANOS & HUMANA/DIGNIDAD & 13 & 5 & 33.3 \\
\hline DERECHOS HUMANOS & CORTE/PENAL & 12 & 9 & 60.0 \\
\hline DERECHOS HUMANOS & DERECHOS/RESPETO & 12 & 7 & 46.7 \\
\hline AMIBIENTE-DESARROLLO & OBJETIVOS/MILENIO & 10 & 6 & 40.0 \\
\hline DERECHOS HUMANOS & DERECHOS/VIOLAR & 10 & 5 & 33.3 \\
\hline AMBIENTE-DESARROLLO & EDUCACION/SALUD & 9 & 9 & 60.0 \\
\hline DESARME & ARMAS/COMERCIO & 9 & 7 & 46.7 \\
\hline AMBIENTE-DESARROLLO & DESARROLLO/HUMANO & 8 & 6 & 40.0 \\
\hline DERECHO INTERNACIONAL & JURISDICCIÓN/OBLIGATORIA & 8 & 4 & 26.7 \\
\hline DESARME & ARMAS/TRATADO & 7 & 7 & 46.7 \\
\hline DERECHOS HUMANOS & DERECHOS/CONSEIO & 7 & 4 & 26.7 \\
\hline AMBIENTE-DESARROLLO & CARBONO/NEUTRAL & 6 & 6 & 40.0 \\
\hline DERECHOS HUMANOS & HUMANIDAD/CRIMENES & 6 & 4 & 26.7 \\
\hline DERECHO INTERNACIONAL & VINCULANTE/JURIDICAMENTE & 4 & 3 & 20.0 \\
\hline DERECHOS HUMANOS & ESTATUTO/ROMA & 4 & 4 & 26.7 \\
\hline DERECHO INTERNACIONAL & CONDICIONES/JURISDICCIÓN & 3 & 3 & 20.0 \\
\hline
\end{tabular}

Fuente: elaboración propia a partir WordSmith 6.0 y discursos de Costa Rica en la UNGA (2002-2015).

El procesamiento informático y la lectura cualitativa de cada una de estas parejas permite establecer estas categorías emergentes. De tal manera, la tabla I presenta las parejas de palabras (palabra I/palabra 2) que guardan cercanía inferior a tres vocablos entre si a lo largo del corpus. Este procesamiento permite obtener el número de repeticiones en que se da esa combinación de palabras a lo largo del corpus. En este ejercicio las combinaciones "HUMANOS/DERECHOS", "DESARROLLO/SOSTENIBLE", "INTERNACIONAL/DERECHO", "GASTO/MILITAR", “INTERNACIONAL/CORTE” y “ARMAS/NUCLEARES” se destacan como las que más repiten y como puede verse en la última columna, aparecen un alto porcentaje de los discursos analizados. Igualmente, aparecen otras parejas igualmente relevantes por su presencia en los discursos, aunque se repitan con menor constancia.

Un segundo hallazgo consiste en señalar que ninguna de estas categorías fue el eje central permanente de los discursos estudiados. El cambio de partido de gobierno parece ser un elemento central para explicar el cambio.Así por ejemplo la administración Pacheco se concentró en derechos humanos, la administración Arias en desarme, la Chinchilla en derecho internacional junto con ambiente y desarrollo; mientras que la administración Solís retornó a derechos humanos junto con medio ambiente y desarrollo. Sin embargo, la identidad partidaria tampoco asegura la 
continuidad del contenido e intensidad de las categorías. En la única situación en que produjo una repetición consecutiva de un partido político en el Ejecutivo durante el periodo en estudio (20062010 y 2010-2014), la administración Chinchilla Miranda brindó menos importancia al desarme que la administración Arias. Incluso iniciativas multilaterales vinculadas a las categorías descritas como el Consenso de Costa Rica y Paz con la Naturaleza fueron desplazadas, pese a que su contenido continuó de alguna forma en el discurso.

\section{Gráfico I. Frecuencia del uso de categorías en el discurso de Costa Rica ante la Asamblea General de Naciones Unidas (2002-20I5)}

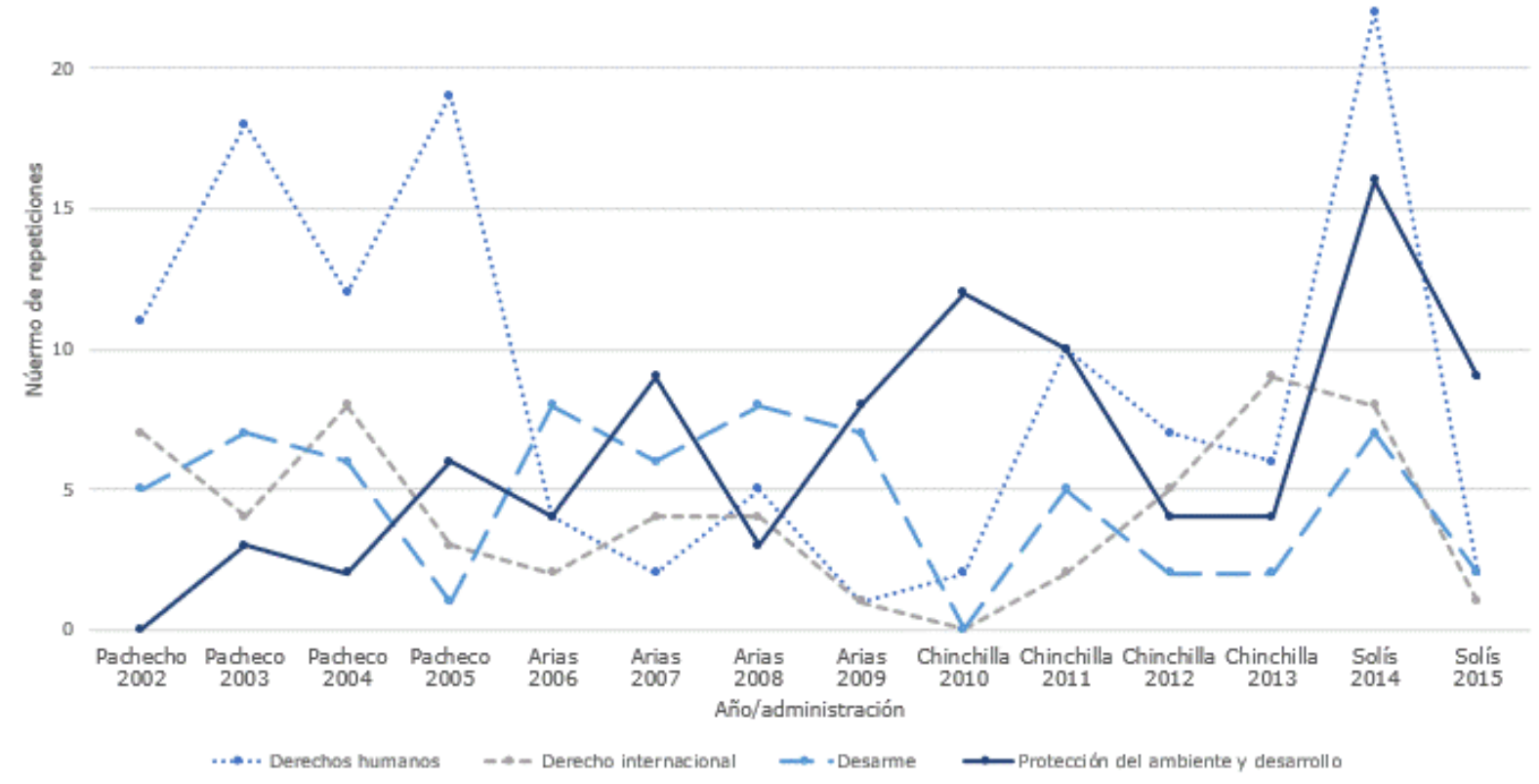

Fuente: elaboración propia a partir WordSmith 6.0 y discursos de Costa Rica en la UNGA (2002-2015).

Ni siquiera puede afirmarse que una categoría se convierte en un eje central permanente por un periodo considerable o al menos dentro de los textos elaborados en el periodo de una administración particular. En esta línea las fluctuaciones en la utilización de ciertas categorías pueden ser anuales, por ejemplo, la administración Pacheco pasó de no ocuparse de la categoría en protección del ambiente en 2002 a darle algún tratamiento en los años siguiente; por el contrario, la administración Solís paso de centrar su discurso 2014 en derechos humanos a no mencionar el tema en el discurso de 20 I5. En la administración Chinchilla las referencias al derecho internacional tampoco son constantes, al igual que la introducción de términos vinculados con la protección del ambiente. La excepción a la regla lo constituye la administración Arias, donde los conceptos vinculados con la categoría desarme se reprodujeron a lo largo de sus cuatro discursos (ver gráfico I). 
Desde esta perspectiva puede concluirse que, a pesar de la permanencia relativa de categorías, las propuestas específicas de Costa Rica que pretenden establecer una sistematización de estas no resisten el cambio de gobierno o el cambio de año. De forma que la variación de la intensidad del uso de categoría también constituye una característica distintiva de los discursos que conforma el corpus de este estudio. En los próximos acápites se mostrará como el contenido de las categorías también ha sufrido cambios constantes con el transcurso del tiempo de las administraciones.

\section{Los contenidos diversos de la categoría de derechos humanos}

Como puede notarse en la tabla 2, la categoría derechos humanos se utiliza prácticamente en todos los discursos, no obstante, la cantidad de repeticiones varía cada año. Junto con esta, se destacan algunos conceptos asociados, específicamente, aquellas referencias a instrumentos e instituciones que controlan y sancionan la violación de los derechos humanos. Por otro lado, existe una continua referencia temas vinculados con la protección de los derechos humanos, por ejemplo, a la Corte Penal (o al Estatuto de Roma que la crea) y al Consejo de Derechos Humanos. Sin embargo, la intensidad y el contenido específico con que esta se ha empleado ha variado en virtud de la administración en que cada discurso sea emitido y las iniciativas que esta establezca en su agenda.

Ahora bien, el peso del concepto dentro del discurso sufre transiciones constantes. De tal forma, este se utilizó con mayor frecuencia en el discurso de las administraciones Pacheco de la Espriella (donde siempre pasó de las II referencias por discurso), Chinchilla (donde sobrepaso al menos las seis referencias en tres discursos) y el primer año de la administración Solís (en que alcanzó 22 referencias), mientras que se presenta una reducción en la administración Arias (en que nunca sobrepasó las cinco referencias). Sin embargo, aún en las administraciones donde el concepto de derechos humanos y temas vinculados fue preponderante se escapó de tener picos y valles de frecuencia a lo largo de los discursos de una misma administración (ver tabla 2). 
Tabla 2. Combinaciones de términos referentes a la categoría derechos humanos utilizadas por año (2002-20 I 5)

\begin{tabular}{|l|c|c|c|c|c|c|c|c|c|c|c|c|c|c|}
\hline \multicolumn{1}{|c|}{ Pal. 1/Pal 2 } & 2002 & 2003 & 2004 & 2005 & 2006 & 2007 & 2008 & 2009 & 2010 & 2011 & 2012 & 2013 & 2014 & 2015 \\
\hline $\begin{array}{l}\text { HUMANOS/ } \\
\text { DERECHOS }\end{array}$ & 5 & 9 & 4 & 10 & 3 & & 2 & 1 & 1 & 6 & 3 & 2 & 10 & 1 \\
\hline $\begin{array}{l}\text { CORTE/ } \\
\text { } E \text { ENAL }\end{array}$ & 1 & & 2 & 1 & & 1 & & & & 1 & 1 & 1 & 3 & 1 \\
\hline $\begin{array}{l}\text { DERECHOS/ } \\
\text { RESPETO }\end{array}$ & & 4 & 3 & 1 & & & 1 & & 1 & & & 1 & 1 & \\
\hline $\begin{array}{l}\text { DERECHOS/ } \\
\text { IIOLAR }\end{array}$ & & 2 & & 1 & 1 & & 2 & & & & & & 4 & \\
\hline $\begin{array}{l}\text { HUMANA/ } \\
\text { DIGNIDAD }\end{array}$ & 5 & 3 & 1 & & & & & & & 1 & 3 & & & \\
\hline $\begin{array}{l}\text { ESTATUTO/ } \\
\text { ROMA }\end{array}$ & & & 1 & 1 & & 1 & & & & & & & 1 & \\
\hline $\begin{array}{l}\text { HUMANIDAD/ } \\
\text { CRIMENES }\end{array}$ & 11 & 18 & 12 & 19 & 4 & 2 & 5 & 1 & 2 & 10 & 7 & 6 & 22 & 2 \\
\hline $\begin{array}{l}\text { DERECHOS/ } \\
\text { CONSEJO }\end{array}$ & & & 1 & 3 & & & & & & & & 1 & 1 & \\
\hline \multicolumn{1}{|c|}{ Total } & 11 & & & & & & 2 & & 1 & 2 & \\
\hline
\end{tabular}

Fuente: elaboración propia a partir WordSmith 6.0 y discursos de Costa Rica en la UNGA (2002-2015).

Desde esta perspectiva, durante la administración Pacheco de la Espriella se dan dos componentes que explican la presencia más frecuente de esta categoría. Por una parte, la creación de la Corte Penal Internacional, del cual Costa Rica participó activamente en la negociación del Estatuto de Roma e incluso ocupó por algunos años la presidencia de la Asamblea de los Estados Parte (Stagno 2012: 304). Por otra, Costa Rica presentó durante esos años una iniciativa de lucha contra todo tipo de clonación humana (incluso la terapéutica), esfuerzo que realizó para la aprobación de una resolución, la 59/280 de la Asamblea General de 2005, la cual fue aprobada por 84 votos contra 34, 37 abstenciones y 36 países no votaron (UNVR, 2020).

En ese contexto, el discurso costarricense ligó claramente el concepto de "dignidad humana" con "derechos humanos" y la lucha contra la clonación, desde una perspectiva más conservadora (Noticias ONU, 2004), que compaginaba con parte de la ideología del partido Unidad Social Cristiana en ese momento en el gobierno, que desde su origen ha estado vinculada con posiciones conservadoras en temas éticos y morales (Aguilar Bulgarelli, 2003; Hernández Naranjo, 20II, p. 132). En tal sentido, en el discurso de 2003, el representante costarricense señalaba:

"El respeto a los derechos humanos se ve amenazado por algunos desarrollos recientes en el campo de la biotecnología. Indudablemente, los avances en las ciencias médicas y en la investigación genética facilitan el desarrollo y descubrimiento de nuevas terapéuticas y técnicas médicas. Sin embargo, esas 
mismas tecnologías crean nuevos desafíos éticos, ya que pueden prestarse para violar los derechos humanos y violentar la dignidad intrínseca de las personas.

Es inaceptable que utilicen embriones humanos para la realización de experimentos científicos, eliminándolos en el proceso. La clonación reduce al ser humano a un simple objeto de producción y manipulación industrial. Esto es moral y jurídicamente reprochable. Costa Rica aboga por una prohibición de todas las formas de clonación humana y ha propuesto un proyecto de resolución en ese sentido, que hoy copatrocinan varias decenas de países" (Saborío, 2003, p. 33).

Este contenido no soportó el cambio de gobierno. La administración Arias Sánchez no tuvo un discurso tan marcado en términos de derechos humanos, mucho menos vinculado a la iniciativa en mención, que desapareció de la agenda costarricense, pese a que el representante costarricense ante las Naciones Unidas, Bruno Stagno, pasó a ocupar el cargo de ministro de Relaciones Exteriores. Cabe resaltar que Stagno nunca figuró dentro de la política electoral costarricense, sino que había estado ligado a figuras de ambos partidos y guardaba una relación muy cercana con el presidente Arias (Stagno, 20I3, p. 10). Asimismo, había tenido una serie de enfrentamientos con las posiciones costarricenses frente a la invasión de los Estados Unidos a Irak (2003).Así las cosas, sin la existencia de una continuidad entre las líneas seguidas en el sistema de Naciones Unidas entre uno y otro gobierno, la administración Arias Sánchez se presentaba a sí misma como progresista y modernizadora en la política internacional de Costa Rica y, como se expondrá más adelante, se concentró en el desarme, un tema vinculado con la agenda tradicional del Presidente Arias (Stagno, 2013, p. 23). También se redujeron las referencias a la Corte Penal Internacional, cuya Asamblea fue presidida por el ministro de Relaciones Exteriores costarricense en ese momento, Bruno Stagno Ugarte. El enfoque se concentró en otros componentes de la imagen costarricense, donde de los derechos humanos tomaban una función secundaria en el engranaje conceptual. De tal forma, con la evidencia disponible, este caso parece respaldar los hallazgos de Merke, Reynoso y Schenoni sobre el peso de las preferencias del presidente en la dirección de la política exterior en América Latina.

La administración Chinchilla Miranda retomó con alguna intensidad las referencias a los derechos humanos, pero lo hizo solo en un año específico el $20 \mathrm{II}$, en este caso al vincularlo con la candidatura costarricense para formar parte del Consejo de Derechos Humanos (elección que fue ganada con 138 votos), asimismo, también eliminó toda referencia a los problemas de la clonación. En esta línea, más que darle un contenido específico a la categoría, se planteaba mayor importancia a fortalecer los instrumentos de ejecución de los compromisos internacionales en las diversas áreas que componen esta materia. Adicionalmente, al impulsar la candidatura costarricense se puntualizaba la imagen costarricense como promotora de cumplimiento y difusión de los derechos humanos en la comunidad internacional:

"Para los pueblos y los líderes comprometidos con esos impulsos fundamentales, la gran pregunta es cómo avanzar a partir de ellos en el mundo que nos cobija. Propongo 
potenciar aún más los conceptos, organismos e instrumentos para la promoción y protección de los derechos humanos. De ahí nuestro interés en participar constructivamente como miembros en las tareas del Consejo de Derechos Humanos. De ahí también nuestra adhesión a los principales convenios y protocolos en la materia, nuestra insistencia en la responsabilidad de proteger a los civiles y nuestro compromiso con la seguridad humana" (Chinchilla, 20I I, p. 22).

El peso de la categoría también puede apreciarse en el primer discurso de la administración Solís Rivera, en esta ocasión vinculado con la fallida candidatura costarricense a la reelección en el Consejo de Derechos Humanos (se produjeron 22 referencias). No obstante, un año después, el discurso bajó drásticamente (dos referencias) y se perfiló más a elementos específicos sobre el contenido de la agenda de derechos humanos, entre ellas las poblaciones migrantes, menores de edad y pueblos indígenas, dado el aumento de este fenómeno, especialmente de niños no acompañados a los Estados Unidos. En otros términos, el discurso pasa a ser más reivindicativo y crítico de la estructura internacional que el que presentó Chinchilla, de forma que en 2015 se planteaba que:

"En materia de derechos humanos, las Naciones Unidas han propiciado un importante desarrollo normativo donde incluso se amplió la frontera de protección, cubriendo un creciente número de sectores vulnerables como niñas y niños, personas con discapacidad, adultos mayores, migrantes y pueblos indígenas. Sin embargo, a pesar de que los principios y las obligaciones están claros y existe una estructura institucional con órganos deliberativos y órganos de ejecución, la situación sobre el terreno en muchas regiones del mundo dista mucho de ser la que queremos y el destino de los recursos no es consistente con los pronunciamientos y las declaraciones" (Solís, 2015, p. 16). 


\section{Gráfico 2. Número de repeticiones de pares de vocablos vinculados con derechos humanos en los discursos costarricenses ante la Asamblea General de Naciones Unidas (2002-20I5)}

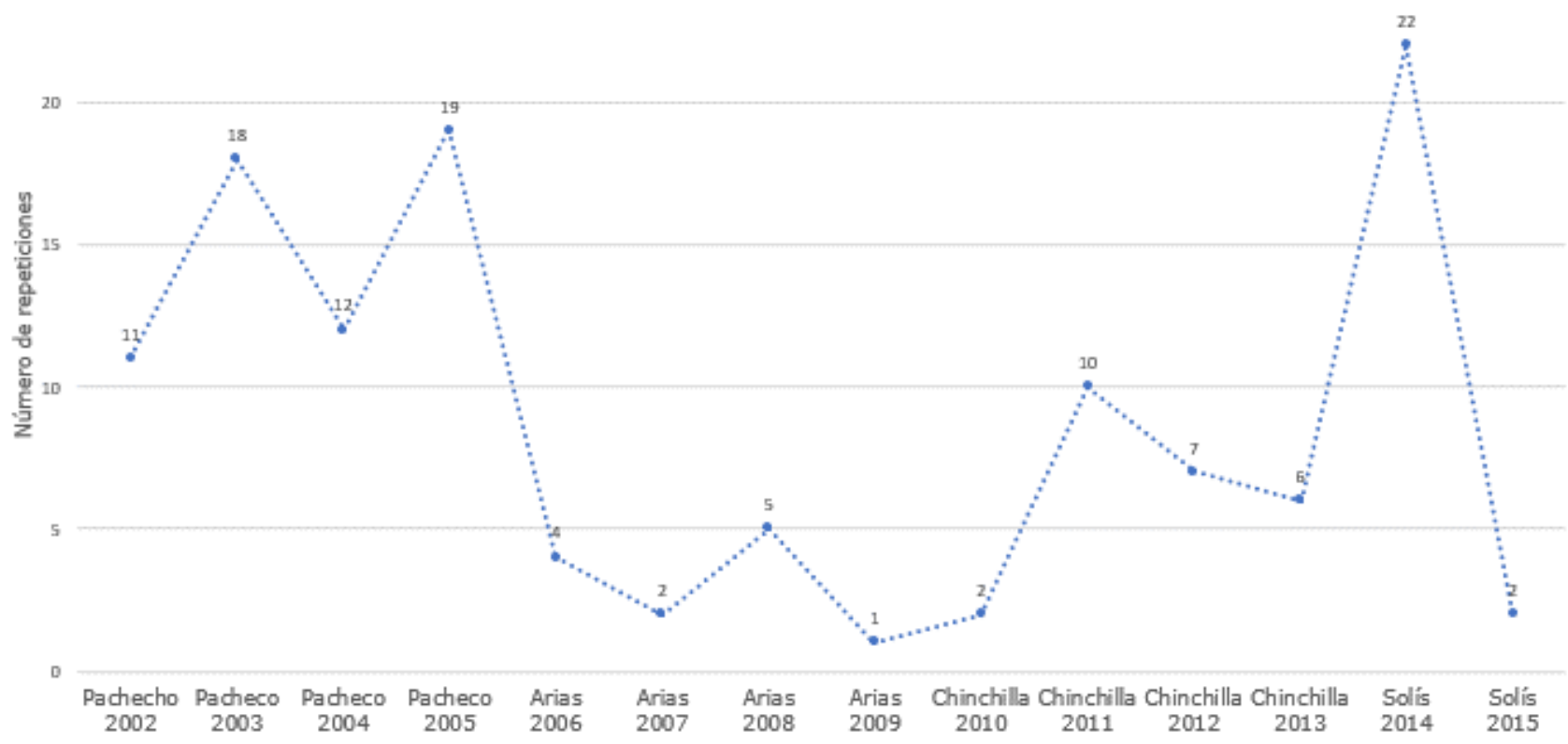

Fuente: elaboración propia a partir WordSmith 6.0 y discursos de Costa Rica en la UNGA (2002-2015).

La revisión de esta categoría del discurso permite determinar que durante los años que comprende este estudio existe una continuidad de uso del concepto, pero esta sufre variantes significativas en cuanto su contenido, dado que se incorporan temáticas específicas o incluso intereses propios del gobierno de turno; que incluso pueden llevar a variantes más conservadoras de los conceptos de derechos humanos. Por otro lado, la mención y defensa de los mecanismos de protección de estos tanto normativos (tratados, declaraciones, etc.), como institucionales (Corte Penal, Corte Interamericana, Consejo de Derechos Humanos), lo cual se encuentra cimentado en la constante búsqueda de los gobiernos de turno por ocupar espacios en esos organismos. Ambos elementos contribuyen a que como muestra el gráfico 2 , la frecuencia de uso de términos vinculados con derechos humanos se caracterice por fluctuaciones evidentes.

\section{El recurso constante de la categoría "derecho internacional”}

A lo largo de su historia, una de las nociones identitarias Costa Rica ha sido presentarse como un país respetuoso del derecho internacional, cuyos primeros esbozos se encuentran en el siglo XIX (Cascante, 20I4; Sáenz, 20I3). Por ende, no resulta extraño que se presenta como una de las categorías básicas del discurso costarricense. Asimismo, constituye uno de los que menos cambios ha sufrido a lo largo de periodo que cubre el corpus estudiado. De tal manera, como puede observarse en la tabla 3, el concepto aparece en II de los 14 discursos, y otros términos vinculados con este que es la Corte Internacional de Justicia aparece en I0. Por otra parte, aunque 
menos frecuentemente, aparecen otras referencias a la obligatoriedad del derecho internacional y su importancia en el sistema internacional.

Tabla 3. Combinaciones de términos referentes a la categoría derecho internacional utilizadas por año (2002-20I5)

\begin{tabular}{|c|c|c|c|c|c|c|c|c|c|c|c|c|c|c|}
\hline Pal. 1/Pal 2 & 2002 & 2003 & 2004 & 2005 & 2006 & 2007 & 2008 & 2009 & 2010 & 2011 & 2012 & 2013 & 2014 & 2015 \\
\hline $\begin{array}{l}\text { INTERNACIONAL/ } \\
\text { DERECHO }\end{array}$ & 1 & 2 & 2 & & 2 & 3 & 3 & 1 & & 2 & 2 & 4 & 4 & \\
\hline $\begin{array}{l}\text { INTERNACIONAL/ } \\
\text { CORTE }\end{array}$ & 2 & 1 & 2 & 2 & & 1 & 1 & & & & 1 & 5 & 4 & 1 \\
\hline $\begin{array}{l}\text { JURISDICCIÓN/ } \\
\text { OBLIGATORIA }\end{array}$ & 3 & 1 & 3 & & & & & & & & 1 & & & \\
\hline $\begin{array}{l}\text { CONDICIONÉ5/ } \\
\text { JURISDICCIÓN }\end{array}$ & 1 & & 1 & 1 & & & & & & & & & & \\
\hline $\begin{array}{l}\text { VINCULANTE/ } \\
\text { JURIDICAMENTE }\end{array}$ & & & & & & 1 & & & & & & & & \\
\hline Total & 7 & 4 & 8 & 3 & 2 & 4 & 4 & 1 & 0 & 2 & 5 & 9 & 8 & 1 \\
\hline
\end{tabular}

Fuente: elaboración propia a partir WordSmith 6.0 y discursos de Costa Rica en la UNGA (2002-2015).

En este orden de ideas, la línea del discurso ha sido más constante, pues se ha dirigido (con diferencia de intensidad en un punto focalizado) en establecer la obligatoriedad de la normativa internacional, así como en la obligación de los actores estatales de acordar normas jurídicamente vinculantes para asuntos concretos que preocupan a buena parte de los países (medio ambiente, comercio de armas convencionales o prohibición de armas nucleares). En algunos momentos, esa necesidad se ha vinculado con referencias a la función de la Corte Internacional de Justicia, por ejemplo, en el discurso de 2005 se planteaba que:

"Resaltamos la importancia de la justicia y el derecho en las relaciones internacionales $y$, por ello, reafirmamos nuestra confianza en la Corte Internacional de Justicia como el mejor mecanismo para la solución pacífica de las controversias. Quisiéramos, por ello, urgir a todas las naciones, a aceptar sin condiciones la jurisdicción de la Corte. Llamamos a los Estados que hayan hecho reservas a su aceptación de la jurisdicción de la Corte a retirarlas" (Vargas, 2005, pp. 18-19).

Pese a que las referencias al respeto a estos entes resultan constantes a lo largo de los textos, como colige en la tabla 3 y el gráfico 3, el punto de mayor intensidad en esta perspectiva 
discursiva se alcanzó entre los discursos del 2012 al 2014 (un total de 22 referencias a la categoría en cuestión), años en que se produce un fuerte conflicto limítrofe con Nicaragua, que termina por ser llevado a los estrados de la Corte Internacional de Justicia (Malamud y García Encina 20I I).

\section{Gráfico 3. Número de repeticiones de pares de vocablos vinculados con derecho internacional en los discursos costarricenses ante la Asamblea General de Naciones Unidas (2002-20 I5)}

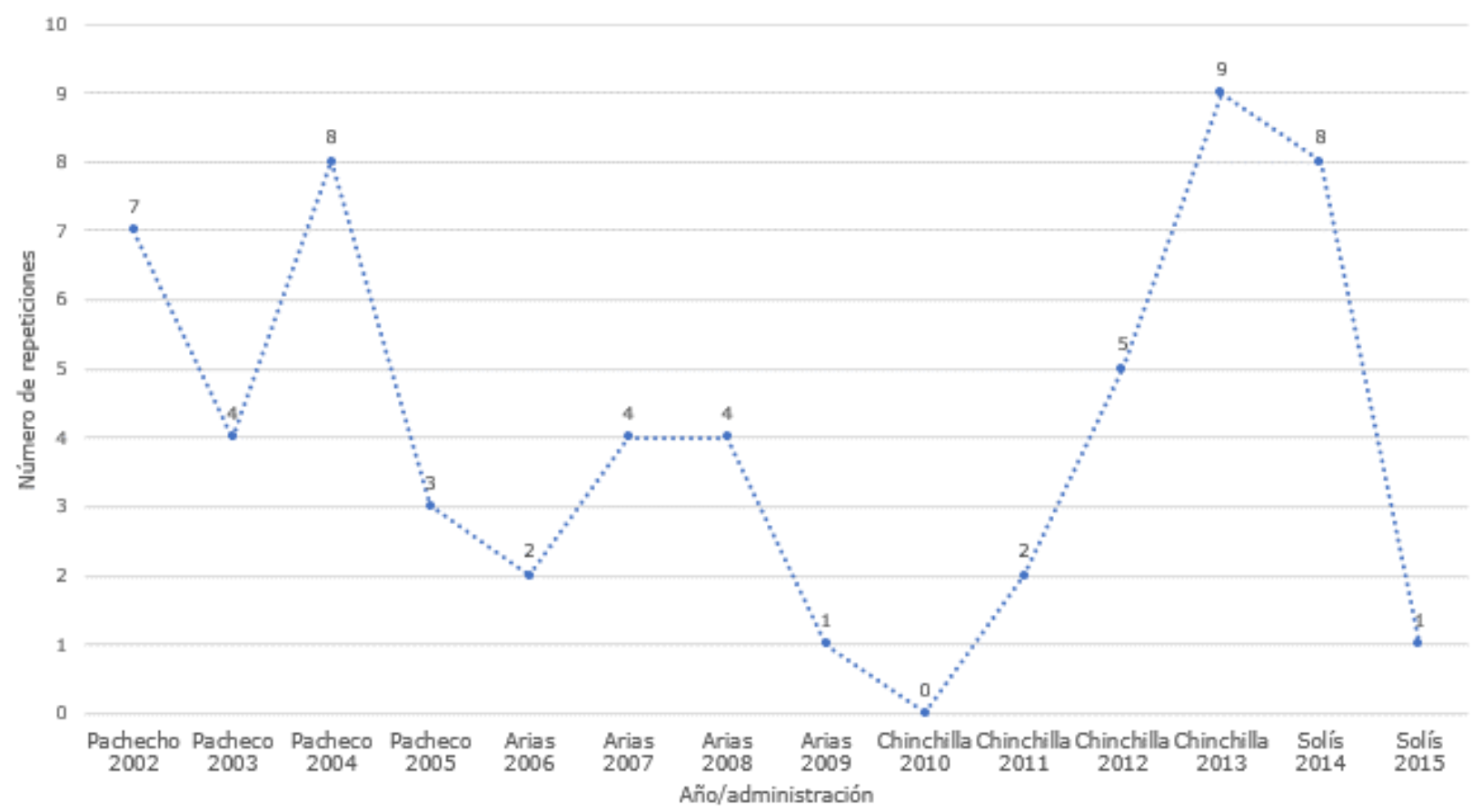

Fuente: elaboración propia a partir WordSmith 6.0 y discursos de Costa Rica en la UNGA (2002-20I5).

Desde esta perspectiva, la conflictividad con Nicaragua y la situación del entorno centroamericano constituye otro condicionante para las alocuciones costarricenses en este foro mundial. En esta ocasión, la relación entre derecho internacional, identidad y diferencias con el régimen político nicaragüense se torna muy evidente, por ejemplo, en este párrafo extraído del discurso de 2013:

"Además de ser instrumento de gobernabilidad global y protección de bienes públicos universales, el derecho internacional tiene muchas otras dimensiones. Entre ellas están el respeto a la soberanía e integridad territorial de los Estados, la buena voluntad en el abordaje de asuntos limítrofes y el acatamiento de las decisiones de la Corte Internacional de Justicia. Costa Rica es firme creyente y escrupulosa practicante de todas las dimensiones del derecho internacional. Esta actitud contrasta con el irrespeto absoluto del gobierno de 
Nicaragua de las normas más elementales de la conducta y convivencia entre los Estados. Este irrespeto ha conducido a continuas, claras e inaceptables agresiones contra nuestro país y a un burdo desdén por las órdenes de la Corte de La Haya" (Chinchilla, 20I3, pp. 25-26).

Por otra parte, más allá del periodo de conflicto, la incorporación constante de esta categoría mediante diversas combinaciones de términos resulta clave para la elaboración permanente de la identidad internacional de Costa Rica y la noción de potencia moral que esgrime en foros internacionales, pese a que no siempre sea tan evidente, por ejemplo, durante el último año de la administración Arias y el primero de la administración Chinchilla (ver gráfico 3), momento que constituye una excepción en el periodo. Asimismo, el componente en cuestión plantea el reto de las autoridades costarricense de cumplir en la práctica con las obligaciones internacionales, dado que el incumplimiento puede causar una reducción de los efectos positivos del discurso.

\section{Una categoría en evolución: desarme}

El pacifismo ha sido uno de los elementos centrales de la identidad costarricense en el ámbito internacional, dado que le permite proyectarse como una potencia moral, que sostiene a partir de la constante reiteración de no contar con un ejército como una institución permanente. Sin aún precisarse un momento específico, lo cierto es que el desarme se ligó al concepto de pacifismo, lo que ha generado posturas fuertes hacia los procesos de limitación de armamento, tanto nuclear como de armas convencionales. 
Tabla 4. Combinaciones de términos referentes a la categoría desarme utilizadas por año (2002-20I5)

\begin{tabular}{|c|c|c|c|c|c|c|c|c|c|c|c|c|c|c|}
\hline Pal. 1/Pal 2 & 2002 & 2003 & 2004 & 2005 & 2006 & 2007 & 2008 & 2009 & 2010 & 2011 & 2012 & 2013 & 2014 & 2015 \\
\hline $\begin{array}{l}\text { ARMAS/ } \\
\text { TRANSFERENCIA }\end{array}$ & & 1 & 2 & 1 & 1 & 1 & 2 & 2 & & 1 & & & 2 & \\
\hline ARMAS/TRATADO & & & & & & 1 & 1 & 1 & & 1 & 1 & 1 & 1 & \\
\hline $\begin{array}{l}\text { ARMAS/ } \\
\text { COMERCIO }\end{array}$ & 1 & 1 & 1 & & 3 & & & & & & 1 & 1 & 1 & \\
\hline $\begin{array}{l}\text { GASTO/ } \\
\text { MILITAR }\end{array}$ & & 1 & 2 & & 4 & 2 & 5 & 4 & & & & & & 2 \\
\hline $\begin{array}{l}\text { ARMAS/ } \\
\text { NUCLEARES }\end{array}$ & 4 & 4 & 1 & & & 2 & & & & 3 & & & 3 & \\
\hline Total & 5 & 7 & 6 & 1 & 8 & 6 & 8 & 7 & 0 & 5 & 2 & 2 & 7 & 2 \\
\hline
\end{tabular}

Fuente: elaboración propia a partir WordSmith 6.0 y discursos de Costa Rica en la UNGA (2002-2015).

Como muestra la tabla 4, durante el periodo de estudio se produjo una evolución acumulativa de elementos dentro de la categoría desarme. Es así como en la administración Pacheco de la Espriella la concentración de este concepto se dirigió a la prohibición del arsenal nuclear (hay al menos cuatro referencias por discurso en los primeros dos años de la administración y una más en la tercera), así como a la firma de un instrumento vinculante para limitar la transferencia de armas. En tal sentido, se indicaba en el discurso de 2003 (el llamado también se realizó en 2004):

"Consideramos urgente la pronta adopción de una convención, jurídicamente vinculante, que regule el comercio en armamentos.

Urgimos a los Estados que poseen armas nucleares a comprometerse verdaderamente con las negociaciones de desarme nuclear. Llamamos a todos los Estados a renunciar al desarrollo de nuevas armas nucleares y a ratificar los tratados de No Proliferación de Armas Nucleares y de Prohibición Completa de los Ensayos Nucleares" (Saborío, 2003, p. 34).

En la administración Arias Sánchez el desarme pasó a conformar el eje central del discurso político ante la Asamblea, dado que se emplearon durante sus cuatro discursos un total de 31 referencias a términos relacionadas con dicha categoría. A esta se sumó una crítica permanente al alto gasto militar, que pasaron a engrosar esta categoría con un carácter crítico a las grandes potencias productoras y vendedoras de armamento. El hecho que el gobierno de turno había patrocinado la adopción de un tratado de limitación a las transferencias de armas, y que el presidente de turno, Óscar Arias Sánchez, había tenido en su agenda el tema del desarme desde 
la década de 1990 mediante la Fundación Arias para la Paz y el Progreso presentase una iniciativa en esa línea a finales de la década de 1990 explica el aumento en la frecuencia de la categoría en cuestión (Domenech, 2013, p. 5).

Asimismo, al desarme le fueron vinculadas otras categorías como desarrollo económico y ayuda oficial al desarrollo creando una red conceptos que se organizaron con alguna sistematización en iniciativas políticas. Sin embargo, se redujo drásticamente la relevancia de las referencias a las armas de destrucción masiva. La tabla 4 permite observar estos cambios que demuestran nuevamente la constancia de categorías, pero inconstancia de su contenido.

Precisamente, el discurso de 2006 muestra tales diferencias. En esa ocasión se hicieron referencias fuertes y muy específicas en torno al gasto militar y la venta de armamento de los países desarrollados a los subdesarrollados:

"Desde hace mucho tiempo he sostenido que la lucha por el desarrollo humano está unida a la causa del desarme y la desmilitarización. Ciertamente, no es un blasón de honor para nuestra especie que el gasto militar mundial haya sobrepasado en 2005 un trillón de dólares, la misma cifra que tenía en términos reales al acabar la guerra fría y ocho veces más que la inversión anual requerida para alcanzar en una década todos los objetivos de desarrollo del Milenio en todos los países.

La inversión que hacen hoy en sus fuerzas armadas los países más industrializados de la tierra, responsables del $83 \%$ del gasto mundial en armas, es 10 veces superior a los recursos que dedican a la ayuda oficial para el desarrollo. Para los Estados Unidos de América, el país más rico del planeta, esa cifra es, por lo menos, 25 veces superior. ¿Qué es esto, sino una muestra elocuente del extravío de las prioridades y de la más profunda irracionalidad?" (Arias, 2006, p. 22).

En este entramado la administración Arias Sánchez desarrolló una iniciativa vinculada con la "distribución ética" de la cooperación internacional y la promoción del desarme a la cual se denominó el "Consenso de Costa Rica":

"Puedo decirles que en mi país, los padres y abuelos explican a los jóvenes la curiosa arquitectura de algunas escuelas, en relatos que atestiguan cómo, hace ya muchos años, esas escuelas fueron cuarteles. Puedo decirles que en mi patria, ninguno de sus hijos, hombre o mujer, conoce la opresión, y que no hay un solo costarricense que marche al destierro. Puedo decirles que la mía es una nación de libertad.

Ese es un camino que mi país y yo no estamos dispuestos a abandonar. No sólo eso: es una ruta que queremos que sea la de toda la humanidad. Por eso, hoy les propongo una idea. Les 
propongo que entre todos demos vida al Consenso de Costa Rica, mediante el cual se creen mecanismos para condonar deudas y apoyar con recursos financieros internacionales a los países en vías de desarrollo que inviertan cada vez más en educación, salud y vivienda para su pueblo, y cada vez menos en armas y soldados. Es hora de que la comunidad financiera internacional premie no sólo a quien gasta con orden, como hasta ahora, sino a quien gasta con ética (Arias, 2006, p. 23).

La propuesta fue presentada en todos los discursos de la administración Arias, esta recogía elementos de la construcción histórica de identidad costarricense -que se expresa en las referencias a generaciones pasadas que trasladan su experiencia a las futuras - para legitimar su papel en la comunidad internacional, en este caso, como proponente de iniciativas de "alto valor ético". Sin embargo, esta no pasó de ser una propuesta unilateral, que no tuvo mayor impacto en las formas de la cooperación internacional. En efecto, como se reconoció posteriormente, tampoco suscitó acuerdos entre los países de renta media y mucho menos en los grandes vendedores de armamento, aunque, según el ministro de Relaciones Exteriores, Bruno Stagno, sí permitió la presencia y dirección de Costa Rica de otros foros vinculados con la discusión de los temas de desarme y apalancar la aprobación del Tratado sobre Comercio de Armas (Stagno, 2013, pp. 237 238).

\section{Gráfico 4. Número de repeticiones de pares de vocablos vinculados con desarme en los discursos costarricenses ante la Asamblea General de Naciones Unidas (2002- $2015)$}

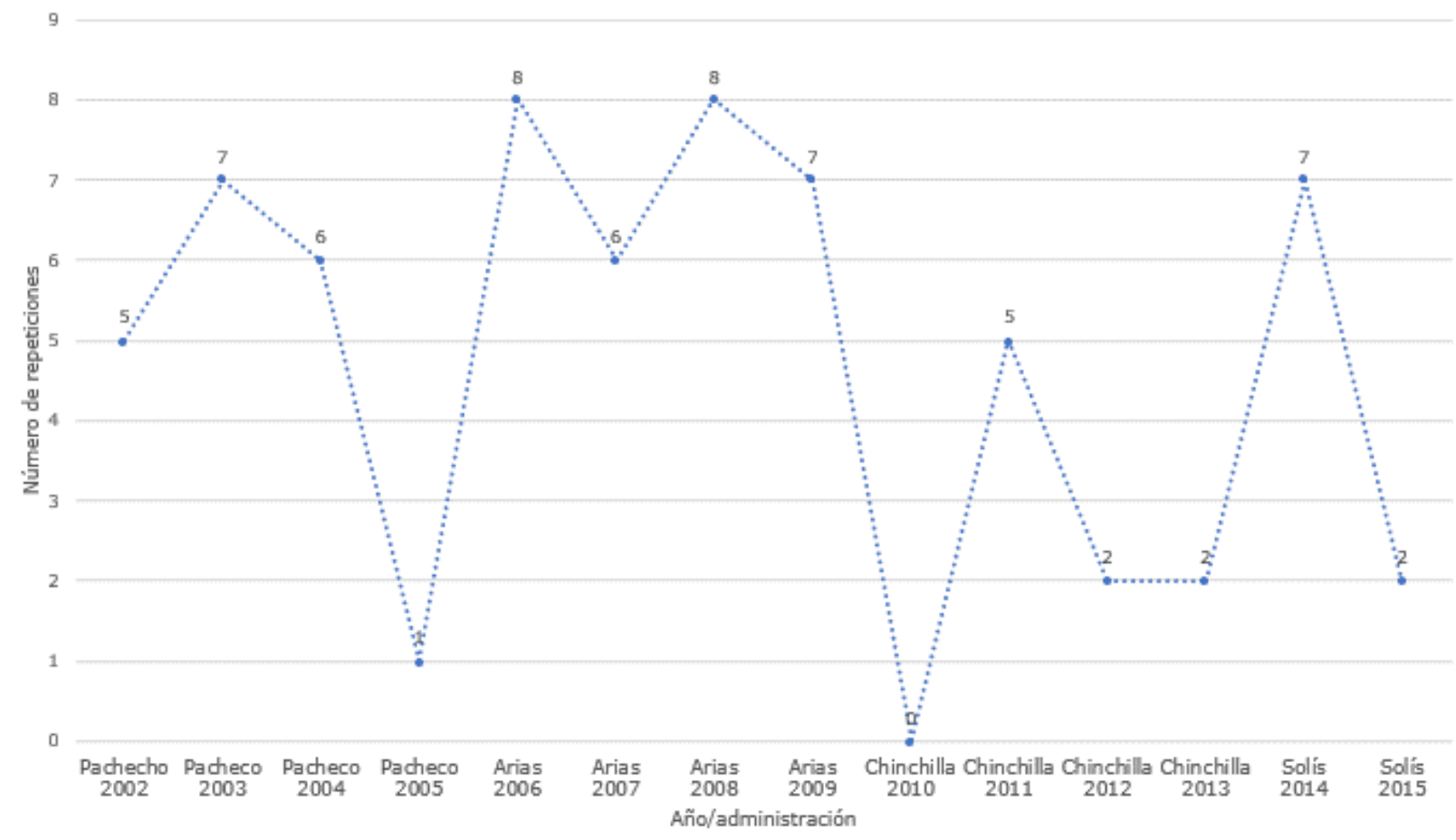

Fuente: elaboración propia a partir WordSmith 6.0 y discursos de Costa Rica en la UNGA (2002-2015). 
Aunque, como muestra el gráfico 4, las referencias sobre el desarme se mantuvieron, este dejó de constituir el concepto central de los discursos a partir de 2010, con el cambio a la administración Chinchilla Miranda, aunque esta también perteneciese al PLN. De tal manera, pese a que hay algunas referencias al tratado de transferencia de armas y las exhortaciones a la prohibición de armas nucleares, químicas y bacteriológicas no hay tanta consistencia como se aprecia durante los años de la administración Arias Sánchez, al punto que se eliminó del discurso cualquier tipo de referencia al denominado "Consenso de Costa Rica".

Posiblemente, a esto contribuyeron las desavenencias que se presentaron entre el gobierno saliente y el entrante en diversos ámbitos, estas en el caso de la conducción de las relaciones exteriores culminó con la renuncia del exministro Stagno a la jefatura de misión en la delegación costarricense en las Naciones Unidas, nombramiento que se había acordado previamente en la transición entre Arias Sánchez y Chinchilla Miranda (La Nación, 2010). Estos hechos refuerzan la hipótesis de que el contenido e intensidad de las categorías está condicionada por los cambios de gobierno y las preferencias de las personas que se encuentren a cargo de esta, pese a que se trate de la misma agrupación política y pueden compartir algunos lineamientos ideológicos.

La categoría en cuestión vuelve a tener un crecimiento durante el primer año de gobierno del PAC, dada la cercanía de la Asamblea General con la entrada que el Tratado de Comercio de Armas en diciembre de 2014. Sin embargo, esta decae en segundo año (último discurso que comprende el corpus); lo que constituye un nuevo ejemplo de las fluctuaciones del discurso costarricense, pese a que algunas iniciativas cuenten con relativo éxito en el foro

\section{Una categoría con cambios nominales y estructurales: "protección del ambiente y desarrollo"}

Con anterioridad al periodo de documentos estudiando en este texto, los discursos de Costa Rica habían incorporado la categoría de protección ambiental. desde antes del periodo bajo estudio relacionado con el concepto de protección ambiental. Según lo muestra la tabla 5 , este se encuentra aparejado con la categoría desarrollo sostenible, por lo que deben considerarse como una unidad de análisis conjunta. 
Tabla 5. Combinaciones de términos referentes a la categoría protección del ambiente-desarrollo utilizadas por año (2002-20I5)

\begin{tabular}{|c|c|c|c|c|c|c|c|c|c|c|c|c|c|c|}
\hline Pal. 1/Pal 2 & 2002 & 2003 & 2004 & 2005 & 2006 & 2007 & 2008 & 2009 & 2010 & 2011 & 2012 & 2013 & 2014 & 2015 \\
\hline $\begin{array}{l}\text { DESARROLLO/ } \\
\text { SOSTENIBLE }\end{array}$ & & 2 & & 3 & 1 & 1 & 1 & 2 & 3 & 1 & 1 & 2 & 7 & 6 \\
\hline $\begin{array}{l}\text { EDUCACIÓN/ } \\
\text { SALUD }\end{array}$ & & & 1 & & 1 & & 1 & 1 & 1 & 1 & & 1 & 1 & 1 \\
\hline $\begin{array}{l}\text { DESARROLLO/ } \\
\text { MILENIO }\end{array}$ & & & & 1 & 1 & 1 & & & 5 & 1 & & 1 & 3 & \\
\hline $\begin{array}{l}\text { CAMBIO/ } \\
\text { CLIMÁTICO }\end{array}$ & & & & & & 5 & & 3 & 0 & 2 & & 1 & 4 & 1 \\
\hline $\begin{array}{l}\text { CARBONO/ } \\
\text { NEUTRAL }\end{array}$ & & & & & & 1 & 1 & & 1 & 1 & 1 & & & 1 \\
\hline $\begin{array}{l}\text { DESARROLLO/ } \\
\text { HUMANO }\end{array}$ & & 1 & 1 & & 1 & & & 2 & 2 & & 1 & & & \\
\hline $\begin{array}{l}\text { OBJETIVOS/ } \\
\text { MILENIO }\end{array}$ & & & & 2 & 1 & 1 & & & & 4 & 1 & & 1 & \\
\hline Total & 0 & 3 & 2 & 6 & 4 & 9 & 3 & 8 & 12 & 10 & 4 & 4 & 16 & 9 \\
\hline
\end{tabular}

Fuente: elaboración propia a partir WordSmith 6.0 y discursos de Costa Rica en la UNGA (2002-2015).

Cabe resaltar que del análisis cualitativo del texto puede colegirse que la "protección ambiental" aparece generalmente ligada a iniciativas presentadas en el ámbito multilateral, a la cual se le asigna un nombre específico para ser presentada con mayor contenido propositivo a la comunidad internacional, lo que permite a las autoridades presentar al país como un actor importante, pese a su debilidad material, en ese ámbito. Estas iniciativas se encuentran dentro de la agenda de administraciones específicas y su contenido permanece en el discurso. Por ejemplo, en 2003, la administración Pacheco de la Espriella, se planteó la relación entre derechos humanos y medio ambiente; en 2004 se planteó que:

“...el principio que Costa Rica quisiera ver reconocido y practicado por la comunidad internacional es el de que:

- A mayor respeto y vigencia de los derechos humanos y laborales;

- A mayor protección del medio ambiente y a menor gasto militar en beneficio de la inversión social,

Más amplias deberían ser las oportunidades de los Estados en el acceso a la cooperación internacional, el crédito y a los mercados sí como al pago de precios justos que interioricen esos costos.

No es justo que se castigue a las Naciones pobres [...] como Costa Rica..." (Pacheco, 2004, pp. 28-29). 
La administración Arias retomó tal abordaje y le brindó una presentación más sistemática que llevó a la iniciativa "Paz con la Naturaleza", la cual estaba vinculada con el "Consenso de Costa Rica", al que se hizo referencia anteriormente, dado que ambas ligaban cooperación para el desarrollo con el avance en derechos humanos y protección ambiental. De tal forma, la administración — que se consideró a sí misma como modernizadora de la política exterior costarricense (Stagno, 2013, pp. 24-25) — pretendió convertir categorías históricas del discurso en iniciativas internacionales con consecuencias específicas, aunque no tuviesen posibilidades de éxito, dados las estructuras internacionales existentes en esas materias. Específicamente, en el discurso de 2009, el entonces presidente Arias, indicaría:

"Quedan pocas semanas para la Conferencia sobre el Cambio
Climático en Copenhague, donde cada país deberá asumir
compromisos mucho mayores que los actuales. Mi pequeño
país, Costa Rica, acudirá a la cita con la frente en alto, porque
unilateralmente, y a fuerza de grandes sacrificios, nos hemos
impuesto metas cada vez más elevadas. Hemos lanzado una
iniciativa conocida como Paz con la Naturaleza, con la que
nos proponemos, entre otras cosas, convertirnos en un
país neutral en emisiones de carbono para el año 202I. En
buena medida, esto es posible gracias a que llevamos casi
cuatro décadas protegiendo nuestro territorio, reforestando
nuestros bosques y resguardando nuestras especies naturales.
También porque, al mismo tiempo que abolimos nuestro
ejército, creamos una institucionalidad pionera en la búsqueda
de fuentes renovables de energía. En la actualidad, más del $95 \%$
de nuestra electricidad proviene del agua, del viento, del fondo
de la Tierra o de los rayos del sol” (Arias, 2009, p. I7).

En la administración Chinchilla Miranda el tema de protección del ambiente aumentó su importancia relativa en los discursos, especialmente en los primeros dos años cuando se contabilizan 12 y 10 referencias, pese a que no se utilizó la iniciativa Paz con la Naturaleza elaborada durante la administración de Arias (ambas del PLN), el contenido se mantuvo. Este cambio de nomenclaturas pudo deberse a las mismas razones esbozadas para el "Consenso de Costa Rica": poco éxito internacional y los desacuerdos señalados en la transición entre Arias y Chinchilla.

La administración Chinchilla Miranda realizó un esfuerzo conceptual relevante al dejar claramente establecidas las relaciones entre desarrollo y ambiente, lo cual fue el resultado de la evaluación de los Objetivos del Milenio (tienen cinco referencias), y se empleó con mayor constancia el término de desarrollo sostenible (se repite un total de siete veces, dado que los Objetivos del Milenio hacen tal ligamen). Esta puede apreciarse en el siguiente pasaje del discurso de 2012:

"Costa Rica adoptó la sostenibilidad como modelo de desarrollo hace varios años, $y$ ha asumido sus responsabilidades nacionales. Hemos aumentado nuestra cobertura boscosa. 
Generamos el $90 \%$ de nuestra energía mediante fuentes renovables. Más del $25 \%$ de nuestro territorio son parques nacionales, y nos hemos impuesto la meta de convertirnos en un país carbono neutral en 202I. Pero estas y muchas otras iniciativas de los pequeños países servirán de poco sin el compromiso de los mayores emisores de carbono y sin la cooperación internacional para la mitigación y adaptación en las naciones más vulnerables" (Castillo, 2012, p.35).

En los discursos de la administración Solís Rivera, por la cercanía con la celebración de la Cumbre de Naciones Unidas sobre Cambio Climático en París en 2015, se produce un aumento a las referencias a la identidad nacional costarricense como arquetipo de "desarrollo sostenible" (ver tabla 5, donde el término se repite 13 veces en dos años), así como las referencias a la meta de carbono neutralidad en el 2021, que provenían de las administraciones Arias y Chinchilla, aunque con otras denominaciones. Cabe señalar que en los últimos lustros se ha ligado de forma distinta el concepto de paz al de desarrollo sostenible y la protección del medio ambiente, pues este no funciona como una consecuencia de la primera, sino como una causa para la convivencia. En esta línea se refuerza la idea identitaria la de excepcionalidad costarricense, según la que al tomar el desarme y la protección del medio ambiente como una decisión historia posibilitó una distribución singular de los recursos del país y que facilitó su desarrollo, lo que terminó por diferenciarlo de los demás países del hemisferio. Como ejemplo de esta línea, durante el discurso de 2014, en la administración del primer presidente del PAC, se señaló:

"Estoy convencido que la nueva Agenda de Desarrollo Sostenible debe ser un instrumento orientado a la acción, con objetivos precisos, metas claras e indicadores que nos permitan su medición y monitoreo. Además, debe ser el producto de un amplio consenso internacional, alcanzado en procesos abiertos y transparentes de negociación que, incluyan no solo a los Estados sino también a otros actores internacionales y a las organizaciones de la sociedad civil, cuya experiencia en esta materia enriquecerá sustancialmente el acuerdo final.

Nos enfrentamos ante la más grave amenaza de nuestra historia: la propia sobrevivencia de nuestra especie. Las acciones frente a esa amenaza no pueden seguir siendo tímidas.

Todo lo contrario. Toda política pública, nacional e internacional, debe incorporar el cambio climático como un factor determinante.

Costa Rica celebra la clara visión del Secretario General de convocar, al inicio de esta Asamblea General, la Cumbre sobre el Clima. Este es el momento de demostrar el compromiso político para alcanzar un instrumento jurídicamente vinculante sobre el cambio climático para el 20 I5" (Solís, 20 I4, p. I2). 


\section{Gráfico 5. Número de repeticiones de pares de vocablos vinculados con protección del ambiente y desarrollo en los discursos costarricenses ante la Asamblea General de Naciones Unidas (2002-2015)}

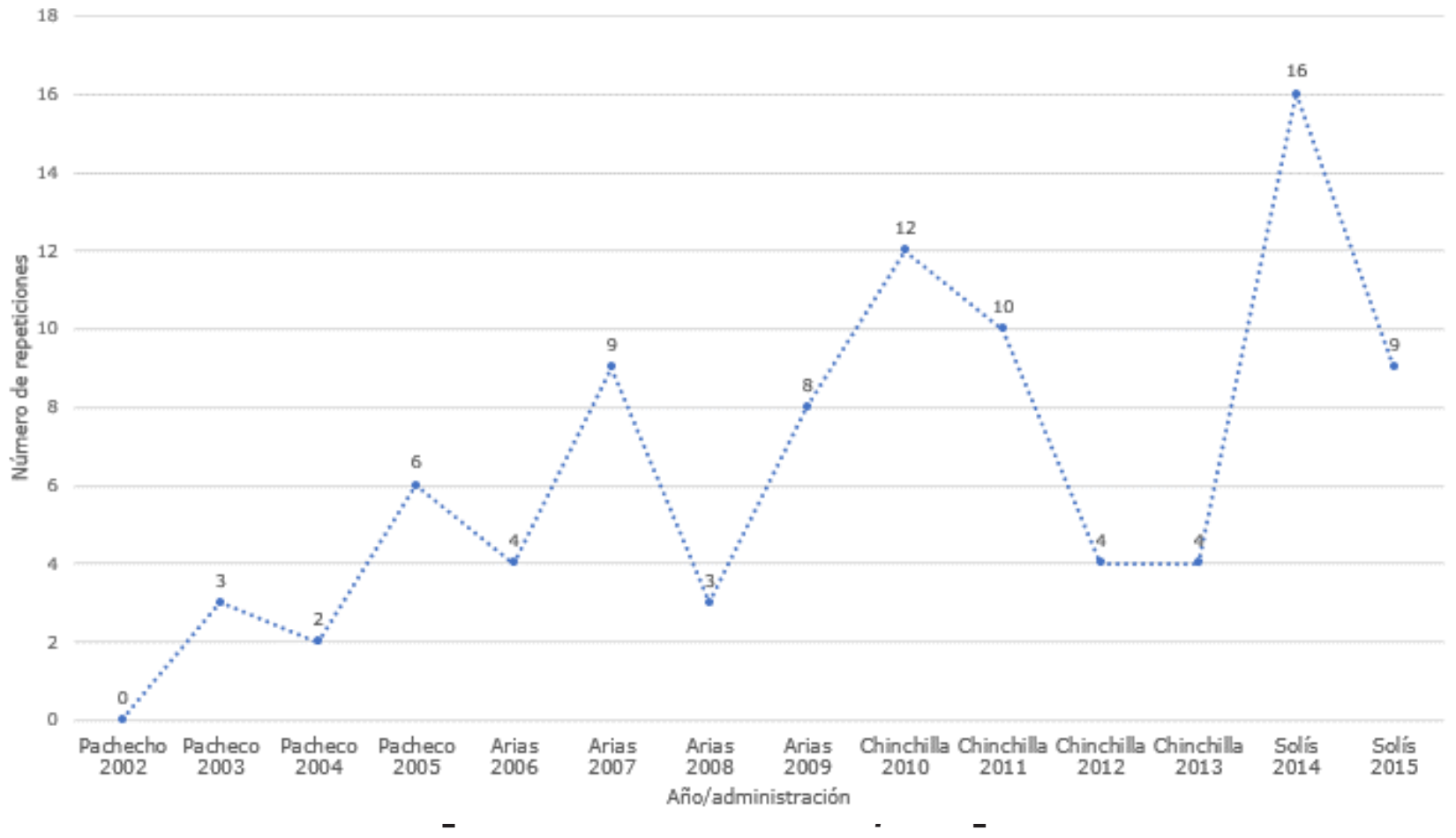

Fuente: elaboración propia a partir WordSmith 6.0 y discursos de Costa Rica en la UNGA (2002-2015).

En definitiva, pese a que de forma creciente el concepto ambiental y su ligamen con desarrollo se ha hecho más evidente en los discursos costarricense en la Asamblea General (ver gráfico 5), y se han establecido ligámenes entre ambiente y desarrollo con otras categorías del discurso costarricense, especialmente, a través del concepto de desarrollo sostenible; lo cierto es que en las autoridades costarricenses parecen incapaces de mantener iniciativas concretas que sistematicen dichas conceptualizaciones en el mediano plazo. En esta línea, la inconstancia de las propuestas que son presentadas en el Debate General y llevadas a los organismos internacionales, específicamente a la Asamblea General, parece ser una característica que debilita el poder blando costarricense en estos foros, sin embargo, esta hipótesis debe ser comprobada mediante una investigación empírica más profunda.

\section{Conclusiones}

Un análisis cuantitativo y cualitativo de los discursos costarricense en la Asamblea General demuestra que a lo largo del tiempo se dan categorías constantes en este foro, sin que esto implique que son también dominantes en el ámbito de su política bilateral o regional, para lo cual se requeriría otro abordaje. Por consiguiente, este artículo ha descrito los grandes patrones del discurso de Costa Rica en los últimos lustros. Este uso tiene dos características: por una 
parte, la intensidad en la utilización de determinadas categorías varía según el gobierno que se encuentre a cargo y; por otra parte, los contenidos de los conceptos tienden, aunque con algunas excepciones (caso de la iniciativa de la "clonación humana") a ser acumulativos y no sustitutivos. En esta línea, derechos humanos fueron profusamente utilizados durante las administraciones Pacheco y el primer año de la administración Solís; desarme fue la categoría fundamental de la administración Arias, mientras que categoría derecho internacional sigue una línea constante, pese a que es evidente una menor frecuencia de uso frente a otras categorías. Por último, protección del ambiente y desarrollo tiene altos y bajos a lo largo del corpus, pero tiende a incrementar en aquellos años con grandes citas internacionales sobre la materia, de forma que en los últimos discursos del periodo es más evidente su presencia.

La fluctuación,por consiguiente,es paradójicamente una constante en discurso costarricense. Incluso iniciativas multilaterales vinculadas a las categorías descritas como el Consenso de Costa Rica (desarme-desarrollo) y Paz con la Naturaleza (ambiente) fueron desplazadas, pese a que su contenido continuó de alguna forma en el discurso, lo que muestra una de las debilidades del discurso de política exterior costarricense: su falta de constancia al construir estructuras conceptuales complejas. En otros términos, si bien los conceptos son constantes el modo en que estos se ordenan o se vinculan unos con otros varia con el tiempo, lo que evita que el discurso tenga mayor consistencia. En el caso de los discursos costarricense ante la Asamblea General la evidencia recolectada y la contextualización vinculada con los discursos permite identificar los efectos de los cambios de gobierno con una causa fundamental de las fluctuaciones en estos, lo que parece acercarse a los resultados de los recientes trabajos en la región sobre regularidad y cambio en la política exterior. También constituye un condicionante significativo del contenido del discurso la agenda internacional, en el caso costarricense, como país pequeño, tal situación resulta más evidente, dado que las grandes citas internacionales, especialmente aquellas dirigidas a tratar temas que refuerzan las categorías del discurso nacional resultarían fundamentales para comprender las fluctuaciones del discurso, como por ejemplo, lo fueron la cercanía de las cumbres sobre cambio climático (París en 2015) y objetivos del milenio impactan claramente el uso de categorías específicas; o bien, la presentación de candidaturas del país a puestos de especial relevancia en el sistema de Naciones Unidas.

En todo caso, el estudio del discurso en la política exterior costarricense constituye un campo abierto a la propuesta y desarrollo de metodologías novedosas; que necesariamente deben tener enfoques mixtos (cuantitativo-cualitativo). Los futuros estudios en esta materia deben dirigirse a determinar las razones para la permanencia, aunque fluctuante, de las categorías establecidas en esta investigación. Los efectos del desarrollo de una identidad nacional que se establece en las relaciones exteriores podría ser un interesante ligamen para explicar la aparición de estas categorías y su conservación. Este componente puede resultar fundamental para comprender en que grado se fortalecen y legitiman las posiciones costarricenses en la esfera internacional como estado pequeño, así como se construyeron las buenas credenciales que regularmente ha tenido en temas generalmente aceptados por la mayoría de la comunidad internacional.

Referencias

Alden, C.,Aran,A. (2017). Foreign Policy Analysis. Routledge. 
Aguilar Bulgarelli, O. (2003). La forja del partido Unidad Social Cristiana. Juricentro.

Baillat, A., Emprin, F. y Ramel, F. (20I8). On Words and Discourse: From Quantitative to Qualitative. En Devin, G. Resources and Applied Methods in International Relations (pp. I5I-166). Palgrave.

Bardin, L. (2002). Análisis de contenido. Akal.

Baturo, A., Dassandi, N. y Mikhaylov, S. (2017). Understanding state preferences with text as data: Introducing the UN General Debate corpus. Research and Politics, 4 (2). https://journals.sagepub.com/doi/ pdf/I0.II77/2053I680I77I282I.

Blavoukos, S.y Bourantonis, D. (20I4). Identifying parameters of foreign policy change:An eclectic approach. Cooperation and Conflict, 49(4), 483-500. http: doi: I0.I I77/00I08367। 35 I 7568

Benhaïm, Y. y Öktem, K. (20I5). The rise and fall of Turkey's soft power discourse, European Journal of Turkish Studies [Online], 2 I. https://doi.org/l 0.4000/ejts.5275.

Broad, M.y Daddow, O. (2010). Half-Remembered Quotations from Mostly Forgotten Speeches:The Limits of Labour's European Policy Discourse." The British Journal of Politics and International Relations, 12, 205-222. https://doi. org/I0.1 I I I/j. I467-856X.20I0.00404.x

Cascante Segura, C. (20I4). Política exterior e identidad nacional. El caso del asilo al general Gerardo Barrios Espinoza ( I863- |865). Diálogos: Revista Electrónica de Historia, I5 (2), 3-30.

Chilton, P. y Schäffner C. (20I I). Discourse and Politics. En Van Dijk, T. Discourse Studies. A Multidisciplinary Introduction (pp. 303-329). Sage.

Chitty, N. (20I7). Soft Power, Civic Virtue and World Politics. En Chitty, N., Li, J., Rawnsley, G. y Hayden, C. (editores), The Routledge Handbook of Soft Power. Routledge.

Chong, A. (2010). Small state soft power strategies: virtual enlargement in the cases of the Vatican City State and Singapore. Cambridge Review of International Affairs, 23 (3), 383-405. https://doi.org/I0.1080/0955757I.2010. 484048

Daddow, O. y Schnapper, P. (20 I 3). Liberal intervention in the foreign policy thinking of Tony Blair and David Cameron. Cambridge Review of International Affairs, 26 (2), 330-349. https://doi.org/ I0.1080/0955757I.20I2.737763

Domenech, J. (20I3). El Tratado sobre el Comercio de Armas: un hito histórico en la protección de la protección civil. Madrid: Instituto Español de Estudios Estratégicos. http://www.ieee.es/Galerias/fichero/docs_marco/20I3/ DIEEEMII-20I3 TratadoComercioArmas DomenechOmedas.pdf

Facio, G. (1977). Nuestra voz en el mundo. Imprenta Trejos Hermanos.

Foucault, M. (1992). El orden del discurso. Tusquets Editores.

Galal, A.M. (2020). External behavior of small states in the light of theories of international relations, Review of Economics and Political Science, 5 (I), 38-56. https://www.emerald.com/insight/content/doi/I 0. I I08/REPS-I I 20l8-0028/full/html

Hagström, L. y Nordin,A. (2020). China's “Politics of Harmony” and the Quest for Soft Power in International Politics, International Studies Review, 22 (3), 507-525. https://doi.org/ I 0.1093/isr/viz023

Hernández Naranjo, G. (20I I). Partidos políticos y la calidad de la democracia en un contexto de cambios en el sistema de partidos de Costa Rica. Anuario del Centro de Investigaciones y Estudios Políticos, 2, I24-I47.

López, C. y Silva, T. (2015). "El discurso político partidario sobre la política exterior en Brasil y Uruguay (200320 I4).” Revista Uruguaya de Ciencia Política, 24 (especial),67-84.http://www.scielo.edu.uy/scielo.php?script=sci_ arttext\&pid=S1688-499X20 I5000200004\&lng=es\&nrm=iso

Lustig, C. (2016). Soft or Hard Power? Discourse Patterns in Brazil's Foreign Policy Toward South America. Latin American Politics and Society, 58(4), I03-125. http//doi: I0. I I I /laps. I 2004

Malamud, C. y García Encina, C. (201I, 7 de febrero). El conflicto fronterizo entre Costa Rica y Nicaragua: ¿medioambiente, soberanía, narcotráfico o mero instrumento electoral? (ARI). Real Instituto Elcano. http:// www.realinstitutoelcano.org/wps/portal/rielcano_es/contenido?WCM_GLOBAL_CONTEXT=/elcano/ elcano_es/zonas_es/america+latina/ari22-20I I

Maass, M. (20I4). Small states: Survival and proliferation, International Politics 51, 709-72. https://doi.org//0.1057/ ip.2014.31

Mayring, P. (20I4). Qualitative Content Analysis. Theoretical Fundation, Basis Procedures and Software Solutions. LeibnitzInstitute.

Merke, F., Reynoso, D. y Schenoni, L. L. (2020). Foreign Policy Change in Latin America: Exploring a Middle-Range Concept. Latin American Research Review, 55 (3), 4I 3-429. http://doi.org/ I0.25222/larr.380

MREC. (2005). Guía de Política Exterior de Costa Rica. Ministerio de Relaciones Exteriores y Culto de Costa Rica.

Murillo, C. (2008). La política exterior de los estados pequeños. El caso de Costa Rica, Temas de nuestra América, 46, 82-I I3. https://www.revistas.una.ac.cr/index.php/tdna/article/view/7803

Nye, J. S. (2004). Soft Power. The Means to Success in the World Politics. Public Affairs.

Nye, J. S. (2010). Prefacio y capítulo 5 "El Poder blando y la Política exterior americana”, en Soft Power, Public Affairs, New Hampshire, 2004, ps. IX-XIII y I27-I47, Relaciones Internacionales, I4, I I 7- I 40.

Neuendorf, K. (2002). The Content Analysis Guidebook. Sage.

Noticias ONU. (2004, 21 de octubre). Costa Rica asume liderazgo en lucha contra clonación humana. https://news. un.org/es/story/2004/I0/104395 I

Ó Súilleabháin, A. (20I4). Small States at the United Nations: Diverse Perspectives. Shared Opportunities. International Peace Institute. 
Sáenz,J. (20 I3). Historia Diplomática de Costa Rica (1948-1970). Escuela de Relaciones Internacionales de la Universidad Nacional de Costa Rica.

Schreier, Margrit. (20I4). Qualitative Content Analysis. Sage.

Simonoff,A. (1997). Discursos e ideas sobre política exterior en el radicalismo argentino. Relaciones Internacionales, 6 (I2) (s.n.). https://revistas.unlp.edu.ar/RRII-IRI/article/view/ / 887

Stagno, B. (20 I4). Defendiendo la integridad del Estatuto de Roma: los altos y bajos del caso de Costa Rica, 2002-2008." En Boeglin, N., Hoffman, J. y Sainz-Borgo. C. (Ed) La Corte Penal Internacional: una perspectiva latinoamericana (pp. 303-330). Universidad para la Paz.

Stagno, B. (20I3). Los caminos menos transitados: la Administración Arias Sánchez y la redefinición de la política exterior de Costa Rica, 2006-2010. Heredia: Euna.

Thorhallsson, Baldur. 20I2. Small States in the UN Security Council: Means of Influence?. The Hague Journal of Diplomacy, 7, I35-I60. DOI: I0.1163/I87|I9112X628454

UNVR, United Nations Voting Recording. https://www.un.org/en/ga/documents/voting.asp

van Dijk, Teum (2006). Ideología: una aproximación multidisciplinaria. Sevilla: Gedisa.

Welch Larson, D. (1988). Problems of content analysis in Foreign Policy: Notes from the Study of the Origins of Cold War Belief Systems. International Studies Quaterly, 32 (2), 24I-255.

\section{Discursos referenciados}

Arias Sánchez, O. (2006, 19 de setiembre). Discurso en la LXI ${ }^{\circ}$ Asamblea General de las Naciones Unidas. https:// undocs.org/es/A/6I/PV.II

Arias Sánchez, O. (2009, 24 de setiembre). Discurso en la LIX Asamblea General de las Naciones Unidas. https:// undocs.org/es/A/64/PV.6

Castillo Barrantes, E. (2012, I de octubre). Discurso en la LXVII ${ }^{\circ}$ Asamblea General de las Naciones Unidas. https:// undocs.org/es/A/67/PV.19

Chinchilla Miranda, L. (20I I, 24 de setiembre). Discurso en la LXVI ${ }^{\circ}$ Asamblea General de las Naciones Unidas, de 20I I. https://undocs.org/en/A/65/PV.II

Chinchilla Miranda, L. (2013, 23 de setiembre). Discurso en la LXVIII ${ }^{\circ}$ Asamblea General de las Naciones Unidas. https://undocs.org/es/A/68/PV.6

Pacheco de la Espriella, A. (2004, 2 I de setiembre). Discurso en la LIX ${ }^{\circ}$ Asamblea General de las Naciones Unidas. https://undocs.org/es/A/59/PV.3

Saborío, L. (2003, 24 de setiembre). Discurso en la LVIII ${ }^{\circ}$ Asamblea General de las Naciones Unidas.: https://undocs. org/en/A/58/PV. 10

Solís Rivera, L. (20I4, 24 de setiembre). Discurso en la LXVII ${ }^{\circ}$ Asamblea General de las Naciones Unidas.: https:// undocs.org/es/A/69/PV.7

Solís Rivera, L. (20I5, 30 de setiembre). Discurso en la LXX ${ }^{\circ}$ Asamblea General de las Naciones Unidas, 30 setiembre de 2015.: https://undocs.org/es/A/70/PV.19

Vargas Pereira, M. (2005, 22 de setiembre). Discurso en la LX ${ }^{\circ}$ Asamblea General de las Naciones Unidas. 22 de setiembre de 2005.: https://undocs.org/es/A/60/PV.2I 


\section{RELACIONES INTERNACIONALES}

Revista académica cuatrimestral de publicación electrónica Grupo de Estudios de Relaciones Internacionales (GERI)

Universidad Autónoma de Madrid, España

https://revistas.uam.es/relacionesinternacionales

ISSN 1699 - 3950

f facebook.com/RelacionesInternacionales

3. twitter.com/RRInternacional

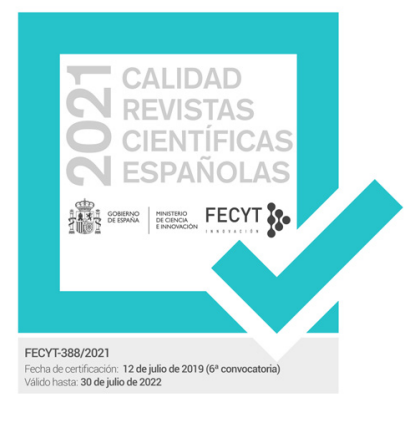

